Croom, A. M. (2013). How to do things with slurs: Studies in the way of derogatory words. Language and Communication, 33, 177-204.

http://dx.doi.org/10.1016/j.langcom.2013.03.008 


\title{
How to do things with slurs: Studies in the way of derogatory words
}

Available online 1 June 2013

http://dx.doi.org/10.1016/j.langcom.2013.03.008

\section{Highlights}

Accounts for slurs and their differential use by in-group and out-group speakers.

Introduces novel analyses of three different uses of slurs.

Integrates slurs with a family-resemblance conception of category membership.

Incorporates interdisciplinary research findings and includes comprehensive references.

Provides a list of seven desiderata to be met by any subsequent analyses of slurs.

\begin{abstract}
This article provides an original account of slurs and how they may be differentially used by in-group and outgroup speakers. Slurs are first distinguished from other terms and their role in social interaction is discussed. A new distinction is introduced between three different uses of slurs: the (a) paradigmatic derogatory use, (b) non-paradigmatic derogatory use, and (c) non-derogatory in-group use. I then account for their literal meaning and explain how a family-resemblance conception of category membership can clarif y our understanding of the various natural-language uses of slurs, (a)-(c). The focus is restricted primarily to race-based and sex-based slurs used in the context of English speakers, and the article concludes with desiderata to be met by any subsequent analyses of slurs.
\end{abstract}

\section{Keywords}

- Slurs;

- Interpersonal behavior and communication;

- Philosophy of language; 
- Pragmatics;

- Sociolinguistics

\section{Introduction}

The use of racial and sexist slurs is highly controversial in society and discussions about their use have been widespread (Kennedy, 2002, Brontsema, 2004 and Browne, 2007). ${ }^{1}$ The use of slurs has often initiated fights and sometimes ended lives (Hoover, 2007, Kiefer, 2010, Fox 10 News, 2010, Fraleigh and Tuman, 2010, BBC News, 2011, Islam, 2011, Siemaszko, 2011 and Wilkinson, 2011), and even President Andrew Jackson (18291837), described as "fiercely jealous of his honor," once killed a man in a duel for slurring his wife Rachel (White House, 2009 and Beschloss and Sidey, 2009). Perhaps unsurprisingly, then, slurs have recently attracted the attention of linguists and philosophers of language (Kaplan, 1999, Richard, 2008, Williamson, 2009 and Anderson and Lepore, 2013). For instance, Jennifer Hornsby has suggested that slurs might count as "hate speech" and so raise questions "about the compatibility of the regulation of [hate] speech with principles of free speech" (2001, p. 129) and Christopher Hom argues that, "the use of an epithet may count as a literal threat, and hence no longer merit freedom of speech protection under the First Amendment" (2008, p. 440). However, despite the fact that the utterance of slurs is derogatory in most contexts, sufficient evidence suggests that slurs are not always or exclusively used to derogate. That is, slurs are frequently picked up and appropriated by the very in-group members that the slur was originally intended to target, which might be done, for instance, as a means for like speakers to strengthen in-group solidarity. So an investigation into the meaning and use of slurs can give us crucial insight into how words can be used with such derogatory impact, and how they can be turned around and appropriated as vehicles of rapport in certain contexts among in-group speakers. Thus, a close analysis of slurs is of interest to the linguist, philosopher of language, legal scholar, and yet others. ${ }^{2}$

\section{What slurs are}

Slurs - such as slut, nigger, bitch, and chink - are terms that are typically used to derogate certain group members and are largely considered among the most taboo and offensive of all linguistic expressions ( Henderson, 2003 and Dutton, 2007). Different slurs target members of different groups, with racial slurs primarily targeting people on the basis of race-based features and sexist slurs primarily targeting people on the basis of sex-based features. Typically characterized as a form of "hate speech [...] directed to a group of people, based on a shared characteristic of that group," slurs are in general considered emotionally charged ${ }^{3}$ derogatory terms that target certain group members on the basis of a descriptive feature such as their race or sex ( Fraleigh and Tuman, 2010, p. 139). Using slurs towards others is of ten considered emotionally offensive, and since the term taboo is used to "describe the lexicon of offensive emotional language" ( Jay, 2009, p. 153), slurs are also characterized as taboo linguistic expressions ( Anderson and Lepore, 2013).

A "taboo" is commonly understood as a "ban or inhibition resulting from social custom or aversion," and as Jay (2009) explains in "The Utility and Ubiquity of Taboo Words," "Taboo words are sanctioned or restricted on both institutional and individual levels under the assumption that some harm will occur if a taboo word is spoken" (p. 153). Since slurs are largely understood to insult, injure, threaten the face of, or impose a negative identity on those that they target (Allen, 1983, Brown and Levinson, 1987, McGlone and Batchelor, 2003 and Rahman, 2012), it has been argued that taboos on their use have been imposed for the purpose of forbidding behavior perceived to be harmf ul towards certain group members (Allan and Burridge, 2006). The taboo nature of slurring terms will be discussed in further detail in the sections that follow, but the next section will first focus on discussing several important ways in which slurring terms differ from other kinds of terms. 


\section{Distinguishing between descriptive, expressive, and slurring terms}

Let us start by taking notice of the fact that slurring terms are distinguishable from other kinds of terms such as descriptive and expressive terms. Examples of descriptive, expressive, and slurring terms are provided below in (1), (2), and (3), respectively:
(1) $S$ is an African American.
(2) $S$ is a fucker.
(3) $\mathrm{S}$ is a nigger.

In (1) we have a descriptive term, African American, and the term is used to identify some descriptive feature of an individual or group, namely, the description of what race that individual or group is. Other examples of descriptive terms include woman and homosexual (Random House Dictionary, 2010), and typically when a speaker says, "S is African American," "S is a woman," or "S is a homosexual," the speaker is describing $\mathrm{S}$, or ascribing the descriptive feature African American, woman, or homosexual, respectively, to S. Of the full list of terms available to a speaker, the list of descriptive terms represents only a subset of this full list, since there are also other kinds of terms available to speakers, such as expressive and slurring terms. Yet this list of descriptive terms represents a rich resource for thinkers and speakers to identify objects, individuals, and groups in primarily value or affect neutral terms. Indeed, the nature of scientific discourse and its aim towards an objective articulation of the natural world relies in large part on a commitment to communicate in terms that are value or affect neutral, thereby purging scientif ic discourse of extraneous subjective contamination (Ayer, 1952, Williams, 1985 and Johnston, 1989). ${ }^{4}$

Yet on the other hand, we also have terms that are not value or affect neutral, but are instead rather expressive of value or affect. For example, in Language, Truth, and Logic, Ayer (1952) claimed that, "in so far as statements of value [...] are not scientific, they are not in the literal sense significant, but are simply expressions of emotion which can be neither true or false" (pp. 102-103). Potts (2007) argues along similar lines in "The Expressive Dimension," suggesting that "expressive content is not propositional, that it is distinct from the meanings we typically assign to sentences," and that "expressives in general manif est this descriptive ineffability," or general lack of descriptive content (p. 177, 176). Yet it is important to notice that these so-called "insignif icant" ( Ayer, 1952, p. 103) or "descriptively ineffable" ( Potts, 2007, p. 176) expressive terms - simply because they do not describe (or "re-present") the world as descriptive terms do with value-neutral language are not as a result of this altogether useless. In fact, expressive terms may serve thinkers and speakers as highly practical communicative resources, especially for aesthetic, moral, and devotional forms of communication ( King-Farlow, 1989). That is, they are thereby thought to offer thinkers and speakers a uniquely expressive resource with which to convey their subjective feelings, perspectives, and emotions. Jay (2009) has even hypothesized that, "The uniquely human facility for swearing evolved and persists because taboo words can communicate emotion information (anger, frustration) more readily than nontaboo words, allowing speakers to achieve a variety of personal and social goals with them (utility)" (p. 153).

An example of an expressive term (fucker) is provided in (2) above, and in contrast with the descriptive term (African American) provided in (1), the expressive term in (2) is not used primarily to identify some descriptive feature of a target individual or group ( Potts, 2008). This is because expressive terms do not generally identify descriptive features of target individuals or groups but rather express the speaker's heightened emotional state ( Ayer, 1952, Jay and Danks, 1977, Haverkate, 1990, Jay, 1992, Jay, 2000, Potts, 2007, Jay and Janschewitz, 2008 and Gutzmann, 2011). Expressive terms like yikes and fuck are terms that speakers learn and conventionally understand as being most apt for expressing their own heightened emotional state (Potts, 2008), and accordingly least apt for the contrasting aim of picking out public items in the external world. This contrasts with descriptive terms, as mentioned above, since descriptive terms like Chinese American and 
woman are terms that speakers learn and conventionally understand as being most apt for picking out public items in the external world, and accordingly least apt for the contrasting aim of expressing their own heightened emotional state. ${ }^{5}$ For instance, in (2) above some speaker can felicitously call $S$ a fucker during an outburst of pure irrational rage, without specifically referring to or basing their utterance on S's race, sex, or other descriptive features at all. So when a speaker says, "S is a fucker," the speaker is primarily expressing their heightened emotional state towards $S$, but not by means of clearly picking out and targeting some specif ic descriptive feature of S. Speakers can have and express feelings of general approval (e.g., hurray, yippie, etc.) or disapproval (e.g., boo, eww, etc.) towards others without having to also articulate and commit to the specif ic features responsible for those feelings, and given that expressive terms are the terms that speakers learn and conventionally understand as being most apt for expressing their own heightened emotional state (Potts, 2008), it is not altogether surprising that speakers of ten use expressive terms in order to do this.

In (3) above we have an example of a slurring term (nigger), which unlike a descriptive term (e.g., African American) is not used by speakers merely to identify public items in the external world, and which unlike an expressive term (e.g., fucker) is not used by speakers merely to express their own heightened emotional state, but rather is instead used by speakers primarily to identify members that possess certain descriptive features (e.g., race) and to derogate them on that basis. For instance, in A Treatise on the Intellectual Character and Civil and Political Condition of the Colored People of the United States, and the Prejudice Exercised Towards Them, Easton (2007) writes that the slur nigger was understood to be "an opprobrious term, employed to impose contempt upon blacks as an inf erior race" (pp. 41-42). Rahman (2012) likewise suggests that "the racist use of nigger criticizes a presumed innate moral and intellectual inferiority of African Americans" (p. 158) and that "nigger became a convenient term for indexing the subhuman characteristics being ascribed to Af rican Americans through this ideology" (p. 143). ${ }^{6}$

By comparing the slurring case (3) with the descriptive case (1) above, it is evident that slurring terms such as nigger differ from descriptive terms such as African American in that the former is commonly understood to carry derogatory force whereas the latter is not ( Hornsby, 2001, Himma, 2002 and Hom, 2008). That is to say, identifying someone as African American is not typically understood as an act of derogation but rather one of straightforward description, whereas identif ying someone as a nigger typically is understood as an act of derogation. Accordingly, this difference between (3) and (1) suggests that slurring terms and descriptive terms are understood by speakers to be of functionally different kinds, and that speakers will in turn use these terms differently in their communicative exchanges.

Another reason that slurring terms differ from descriptive terms is that the former but not the latter pass two paradigmatic tests that are used to identify linguistic items that are non-descriptive (McCready, 2010). In "Varieties of Conventional Implicature," McCready (2010) proposes two tests for identif ying linguistic items that are non-descriptive, with the first identif ying the scope or "scopelessness" of a linguistic item and the second identif ying a linguistic item's behavior under negation or denial (p. 6). I offer an example of the first test below, which shows that descriptive terms in (4) differ in scope from slurring terms in (5).

(4) If I didn't like African Americans, then l'd probably be a racist.

(5) If I didn't like niggers, then l'd probably be a racist.

Since in (4) the descriptive term African American is embedded within the antecedent of the conditional, and since descriptive terms are not understood (and taught to, and learned by, others) to reliably communicate that the speakers using them possess derogatory attitudes in the same way that slurring terms are understood (and taught to, and learned by, others) to reliably communicate this, it is clear that a speaker uttering (4) does not generate the inf erence that they are racist simply by virtue of uttering (4). The speaker of (4) is only committed to saying that they probably would be racist if in fact they did not like African Americans, but that is 
an if they can plausibly deny. So the scope of the descriptive term African American is restricted by the conditional and does not project out to generate inferences about the speaker's communicative intent.

On the other hand, even though in (5) the slurring term niggers is embedded within the antecedent of the conditional, the derogatory force of niggers scopes out of its embedded position to generate the inference that a speaker uttering (5) presumably has racially derogatory attitudes or intent. In "Meaning and Uselessness: How To Think about Derogatory Words," Hornsby (2001) observes that "derogatory words [...] apply to people and are commonly understood to convey hatred or contempt" but that "for each such word, there is [...] another [word] that applies to the same people but whose use does not convey these things - there is, that is, a neutral counterpart" (pp. 128-129). Accordingly, since speakers have a lexical choice regarding how they identify their intended targets - i.e., between (a) opting to use a slurring term (e.g., nigger), which is "commonly understood to convey hatred or contempt" ( Hornsby, 2001, p. 128-129), or instead (b) opting to use a slurring term's "neutral counterpart" (e.g., African American), which is not "commonly understood to convey hatred or contempt" ( Hornsby, 2001, p. 128-129) - that speaker will be prima facie expected to choose the term that they consider most appropriate for identifying their intended target.

Lexical choices are choices that confront all language-users on a regular basis, and Nevala (2004) observes that when a speaker encounters a lexical choice of this kind, "the speaker not only has to take into account his/her relationship with the hearer, but also has to decide how to present the referent in a situationally appropriate manner" (p. 2126). Accordingly, the speaker will be expected to choose (a) just in case the speaker considers it most appropriate to convey hatred or contempt towards their target, or (b) just in case the speaker considers it most appropriate not to convey hatred or contempt towards their target, and further, the speaker will be prima facie expected to be held accountable for their choice. As Gibbs and Van Orden (2012) suggest in "Pragmatic Choice in Conversation," speakers are "aware of their thoughts and intentions, and even what words and syntax to use, as they strategically plan what to say in specific social circumstances" (p. 7; see also Lee and Pinker, 2010), and accordingly, speakers that make the choice of using a slur in the derogatory way that it has typically been used are making a significant choice to which they will of ten be held accountable by others. So the speaker's expressed attitude towards their target - whether that attitude is (a) a derogatory attitude conveying contempt, or (b) a neutral attitude not conveying contempt - is communicated to hearers by way of that speaker's lexical choice of opting to identify their target with (a) or (b), respectively. For if the speaker did not have derogatory attitudes or intent there are many other non-derogatory and neutrally descriptive terms that the speaker could have used instead for the purposes of their communicative action, for instance, the speaker could have said (4) instead. Hagberg (2004) even goes onto propose, in his article "Wittgenstein Underground," that a writer's emotion "is manif est in the language he is presently writing [with] and not hidden in a metaphysical interior. It is language that not only conveys, but more strongly constitutes, the content of the inner self of which we can and do make sense" (pp. 382-383). Considering also that the choice of one's words has often determined whether one lives or dies in real-life situations ( Kiefer, 2010 and Wilkinson, 2011), it is clear that our practical choice of terms of ten carries immense significance for both literary and concrete non-literary cases.

In "The Logic of Indirect Speech," Pinker et al. (2008) suggest that the "literal form of a sentence is consistent with the safest relationship between speaker and hearer" (p. 835), and here I am similarly suggesting that lexical items of a neutral kind (e.g., descriptive terms) are usually consistent with the safest relationship between speaker and hearer, whereas lexical items of a non-neutral kind (e.g., slurring terms) are usually inconsistent with the safest relationship. Thus, speakers may exploit their understanding of the difference in derogatory force between neutrally descriptive terms like those in (1) and non-neutrally slurring terms like those in (2) such that they may strategically choose to use one rather than the other to indicate a difference in their expressed attitude towards the target of their utterance. That is, a speaker may exploit their understanding of the difference in derogatory force between neutrally descriptive terms like African American and nonneutrally charged terms like nigger in order to most aptly communicate to others, through their lexical choice, the corresponding attitude that they are intending to express towards their target. 
We saw that the first test for identif ying linguistic items that are non-descriptive focused on the scope or "scopelessness" of a linguistic item. The second test used to identify linguistic items that are not purely descriptive, to be further discussed here, focuses on an item's behavior under negation or denial. I offer an example of the second test below, which shows that the linguistic behavior of descriptive terms in (6) differs under denial from terms that are not purely descriptive in (7). In examples such as these McCready (2010) points out that "In ordinary denial, the truth of any at-issue [i.e., descriptive] part of a sentence can be called into question" (p. 7). This is evidenced below, where the standard interpretation of B's denial of A is given in $(6 b)$ :

(6a) A: John came to the party last night.

B: That's not true/That's false.

(6b) = John didn't come to the party.

Slurring terms differ from descriptive terms in that their content "does not participate in denials," as evidenced in the example from McCready (2010) provided below (p. 7, 10). Again, the standard interpretation of B's denial of $A$ is given in $(7 b)$ :
(7a) A: Juan is a kraut.
B: That's not true/That's false.
(7b) $\neq$ German people are not bad.

The results of these tests, as McCready (2010) suggests, "supports the conclusion that the negative part of the meaning of Kraut, and, by extension, pejoratives in general [...] are not part of the at-issue [or descriptive] meaning" (p. 10).

Furthermore, by comparing the slurring case (3) with the expressive case (2) above, it is also clear that slurring terms such as nigger differ from expressive terms such as fucker in that the former is commonly understood to target certain descriptive features of targets (e.g., their race) whereas the latter is not. This is further suggested by the examples below:

(8a) S is a fucker, but I deny saying anything about his $[x]^{d}$.

(9a) S is an African American, but I deny saying anything about his $[\mathrm{x}]^{\mathrm{d}}$.

(10a) $S$ is a nigger, but I deny saying anything about his $[x]^{d}$.

Let $[x]^{d}$ represent a variable that admits only of descriptive terms. Substituting descriptive terms for $[x]^{d}$ in the examples shows that the substitution of certain descriptive contents blocks the felicity of descriptive terms in (9) but does not block the felicity of expressive terms in (8). This is suggested in the examples involving substitutions below:

(8b) S is a fucker, but I deny saying anything about his [racial identity].

(9b) S is an African American, but I deny saying anything about his [racial identity].*

(10b) $S$ is a nigger, but I deny saying anything about his [racial identity].*

Notice from the examples above that whereas the expressive case (8) is felicitous on the basis that pure 
expressive terms do not pick out certain specific descriptive features (such as race) and therefore can be felicitously uttered while denying some particular set of descriptive features (such as race) to its target, the slurring case (10) is not likewise felicitous. This suggests that in this respect the slurring case (10) is not like the expressive case (8) but is instead like the descriptive case (9). ${ }^{7}$

The intuition behind this result is straightforward since slurs are usually understood to target descriptive features associated with members of certain classes; for example, nigger typically slurs targets on the basis of their racial description as African American, chink typically slurs targets on the basis of their racial description as Chinese American, faggot typically slurs targets on the basis of their sexual description as homosexual, and so on. In contrast with slurring terms, however, it has been largely assumed in the literature that pure expressive terms like yikes and fuck do not target descriptive classes since they instead express the speaker's heightened emotional state ( Ayer, 1952, Haverkate, 1990, Kratzer, 1999, Potts, 2007 and Jay and Janschewitz, 2008).

This point is not specif ic to racial slurs but is a general point applying to other kinds of slurs such as sexist slurs. Consider the following examples:

(11a) $S$ is a fucker, but I deny saying anything about her $[x]^{d}$.

(12a) $S$ is a woman, but I deny saying anything about her $[x]^{d}$.

(13a) $S$ is a slut, but I deny saying anything about her $[x]^{d}$.

Substituting descriptive terms for $[x]^{d}$ in the examples shows that the substitution of certain descriptive contents blocks the felicity of descriptive terms in (12) but does not block the felicity of expressive terms in (11). This is suggested in the examples involving substitutions below:

(11b) S is a fucker, but I deny saying anything about her [sexual identity].

(12b) S is a woman, but I deny saying anything about her [sexual identity].*

(13b) $S$ is a slut, but I deny saying anything about her [sexual identity].*

It is suggested from these examples that whereas the expressive case (11) is felicitous on the basis that pure expressive terms do not pick out specific descriptive features (such as sexual features) of their targets and therefore can be felicitously uttered while denying that specific descriptive features (such as sexual features) belong to those targets, the slurring case (13) is not likewise felicitous. In this respect the slurring case (13) is not like the expressive case (11) but is instead rather like the descriptive case (12).

It therefore seems evident from the above examples that whereas slurring terms such as nigger and descriptive terms such as African American are sensitive to certain descriptive contents - for instance, those regarding racial features - this is not the case for pure expressive terms such as fucker. For whereas the felicity of utterances involving slurs and descriptive terms can be blocked by continuation clauses containing the negation of the relevant descriptive content, the felicity of utterances involving pure expressive terms such as damn and fucker cannot typically be blocked in this way. Indeed, this point is supported by the fact that, whereas expressive terms such as damn and fucker do not differ in their descriptive content - i.e., Potts (2007) and others have suggested that they have no descriptive content - slurs do in fact seem to be distinguished from one another by virtue of (differences among) their descriptive content. What makes a racial slur $r$ a racial slur is determined by the content of $r$ just as what makes a sexist slur $s$ a sexist slur is determined by the content of s ( Himma, 2002 and Hom, 2008). This point can be further clarified with an example: 
(14a) $S$ is a slut, but I deny saying anything about her $[x]^{d}$.

(15a) $S$ is a nigger, but I deny saying anything about her $[x]^{d}$.

Substituting descriptive terms for $[x]^{\mathrm{d}}$ in the examples shows that the substitution of certain descriptive contents blocks the felicity of the slurring term in (14) but not (15), whereas the substitution of other descriptive contents blocks the felicity of the slurring term in (15) but not (14). This is suggested in the examples involving substitutions below:

(14b) S is a slut, but I deny saying anything about her [racial identity].

(15b) S is a nigger, but I deny saying anything about her [racial identity].*

(14c) S is a slut, but I deny saying anything about her [sexual identity].*

(15c) S is a nigger, but I deny saying anything about her [sexual identity].

Although the sexist case (14) and the racist case (15) both involve utterances the felicity of which are blockable by some descriptive content, it is evident from these examples that they are not both blockable by the same descriptive content. That is to say, that content which blocks the felicity of the sexist slur in (14) does not block the felicity of the racial slur in (15), and that content which blocks the felicity of the racial slur in (15) does not block the felicity of the sexist slur in (14). Resultantly, since slurs are distinguishable from one another by virtue of their descriptive conditions, it follows that slurs must have descriptive contents, and that these contents must possess sufficient differences among their varieties such that they can be aptly distinguished from one another by competent speakers. Accordingly, this difference between (14) and (15) suggests that sexist slurs and racial slurs target group members on the basis of different descriptive features, and that speakers will in turn use these different terms to target different group members in communicative exchanges.

Early in the linguistic and philosophical literature it was assumed that all terms could be neatly partitioned into either purely descriptive or expressive kinds and that these two kinds were fundamentally distinct (Ayer, 1952, Kratzer, 1999 and Potts, 2007). Indeed, in his influential article "The Expressive Dimension," Potts (2007) claimed that "descriptives and expressives are fundamentally different" and that the "descriptive and expressive realms are [...] distinguished not only syntactically (in the semantic types), but also modeltheoretically" (p. 165, 167). However, in this section I showed that slurring terms differ from both descriptive terms and expressive terms in significant ways, and as a result, that slurring terms do not fit nicely into either one of these two categories (insofar as they have traditionally been considered to be mutually exclusive, as in Potts (2007)). This is precisely because slurs possess an interesting combination of properties shared by both descriptive and expressive terms. The analysis here therefore suggests that slurs are of a mixed type, containing both descriptive and expressive elements (for further discussion on other terms that are also of a mixed type, such as moral and aesthetic terms, see Croom, 2010a and Croom, 2012a).

\section{Language and social interaction}

It has been well discussed in the literature that speakers learn the norms governing conversation and the differential uses of terms during socialization into one's linguistic community (Ochs and Schieffelin, 1984, Garrett and Baquedano-Lopez, 2002 and Matthiessen, 2009). Socialization typically refers to "the process through which a child or other novice acquires the knowledge, orientations, and practices that enable him or her to participate effectively and appropriately in the social life of a particular community," and linguistic socialization refers more specif ically to the process through which "children and other novices are socialized 
through the use of language as well as how they are socialized to use language" ( Garrett and BaquedanoLopez, 2002, p. 339). In the literature it has been widely argued that "Linguistic patterns are related to and grounded in the types of social action that they recurrently implement" ( Keevallik, 2010, p. 800; see also Goodwin, 1979 and Goodwin, 1980; Bakhtin, 1981 and Gumprz, 1982; Fox and Thompson, 1990, Lerner, 1991, Ford, 1993, Ochs et al., 1996, Lindstrom, 1999, Sorjonen, 2001, Goodwin, 2007, Couper-Kuhlen and Thompson, 2008 and Anderson, 2008) and that language is "imbued with social meaning through repeated use in contexts that community members are aware of and understand" ( Rahman, 2012, p. 146; see also Bauman and Briggs, 1990, Ochs, 1992, Coupland, 2001, Coupland, 2007 and Hill, 2008). 8 For example, in "Intracultural Tact versus Intercultural Tact" Janney and Arndt (1992) suggest that "growing up to become a normal member of a culture is largely a matter of learning how to perceive, think, and behave as others in the culture do" ( $p$. 30), and in Code of the Street: Decency, Violence, and the Moral Life of the Inner City Anderson (1999) suggests that through such socialization "the child is more completely initiated into a world" (p. 70; see also McDowell, 1996).

Accordingly, since a speaker's knowledge of the use-conditions for the linguistic expressions in their language is vital for their success at interpersonal participation with other interlocutors - just as a chess player's knowledge of the use-conditions for chess pieces is vital for their interpersonal participation with other chess players - it stands to reason that part of the process of linguistic socialization involves learning the useconditions for the terms in one's language and behaving accordingly (Samra-Fredericks, 2010). It is presumably the case then that speakers learn the norms governing the differential uses of descriptive, expressive, and slurring terms - that is, that the first are most apt for neutrally picking out public items in the external world, that the second are most apt for expressing one's own heightened emotional state, and that the third are most apt for targeting certain members on the basis of descriptive features so as to deprecate them on this basis $^{9}$ - during socialization into one's linguistic community. It has been pointed out, for example, that prohibitions on taboo words are often reinforced during child-rearing practices (Jay, 2009), and as Potts (2008) writes about our understanding of the use-conditions for expressive terms in "The Pragmatics of Conventional Implicature and Expressive Content":

\begin{abstract}
As speakers we have strong expectations that uses of [expressive terms such as] damn will correlate with the speaker's being in a heightened emotional state (or wishing to create that impression). In turn, we use it only when we are in such a state (or wish to create that impression). The total effect of these assumptions is that [an expressive term such as] damn is a reliable signal of emotionality. Knowing its use conditions [...] largely involves being attuned to this information. ( $p$.
\end{abstract} 13)

In How To Do Things With Words, Austin (1962) makes a similar point but speaks more generally in suggesting that, "Where, as often, the [linguistic] procedure is designed for use by persons having certain thoughts or feelings [...] then a person participating in and so invoking the [linguistic] procedure must in fact have those thoughts and feelings, and the [conversational] participants must intend so to conduct themselves" (p. 15, 39). Bearing this in mind, I propose the following as a prima facie serviceable characterization of our understanding of the use-conditions for slurring terms:

As speakers we have strong expectations that uses of slurring terms such as nigger will correlate with the speaker's being in a heightened derogatory state with respect to some features of their target (or wishing to create that impression). In turn, we use it only when we are in such a state (or wish to create that impression). The total effect of these assumptions is that a slurring term such as nigger is a prima facie reliable signal of derogation on the basis of target features. Knowing its use conditions largely involves being attuned to this information. 
Evidently, then, the variety of terms that we make use of in everyday discourse are publically available communicative resources that speakers can reliably draw upon in order to communicate and accomplish their practical aims. Further, because "social history endows linguistic resources with social meanings" (Rahman, 2012, p. 142), corresponding to each term representing a category of members are expectations or obligations that are thought to be prototypical or characteristic of members belonging to that category (Samra-Fredericks, 2010). For instance, in categorizing someone as a man one is also thereby applying corresponding expectations and obligations to that person that are prototypical or characteristic of men but not others; in categorizing someone as a pastor one is also thereby applying corresponding expectations and obligations to that person that are prototypical or characteristic of pastors but not others; in categorizing someone as a soldier one is also thereby applying corresponding expectations and obligations to that person that are prototypical or characteristic of soldiers but not others. In short, when we refer to a person with a category or ascribe a category to that person, we are also thereby "evoking particular membership categories and the rights and obligations that pertain to them" ( Samra-Fredericks, 2010, p. 2152; see also Samra-Fredericks, 2003). In Code of the Street, Anderson (1999) goes onto explain that "For many young men, the operating assumption is that a man, especially a "real" man, knows what other men know - the code of the street. And if one is not a real man, one is diminished as a person" (p. 91).

\section{Language and social identity}

Discussing the expectations and obligations associated with the categories we ascribe both to ourselves and to others is important because it renders salient the sociology of linguistic knowledge, and the importance of such publically available knowledge for our ability to strategically interact and communicate with each other in everyday conversational contexts. It further highlights the fact that we are sensitive to the ways that we are categorized, because this in turn influences what others will expect from us and how others will treat us. In effect, how we are categorized reconfigures how people conceive of us and behave towards us, altering their behavioral and communicative strategies in engaging with us. In Interaction Ritual: Essays on Face-To-Face Behavior, Goffman (1967) aptly articulates the way in which people are emotionally invested and committed to the identities that they present to others in society. Because our thoughts and actions must be strategically coordinated and organized in order to act out a particular role or social identity (e.g., one's thoughts and actions must be strategically coordinated and organized in order to act out one's identity qua man, pastor, or soldier, etc.), our emotions are likewise committed to our presentation of "face," or the "positive social value a person effectively claims for himself by the line [i.e., the pattern of verbal and non-verbal acts by which he expresses his view of the situation and through this his evaluation of the participants, especially himself] others assume he has taken during a particular contact" ( Goffman, 1967, p. 5). In other words, because the particular identity and face one commits to presenting in public is associated with particular expectations and obligations, one will be put at cognitive and emotional unease if for some reason the particular identity and face that one is attempting to uphold becomes questioned or challenged. Insof ar as one's identity and face is challenged in this way, that person's right to act in line with that identity is also thereby challenged, with the consequence that they may no longer be able to carry out the practical actions afforded by the identity that they wished to uphold (e.g., the actions proper of a man, pastor, or soldier, etc.).

Accordingly, forms of politeness can be used by speakers to indicate that, at least for the purposes of conversation, the threat of losing one's face and its corresponding rights will not outweigh the possible value of engaging in the conversation itself, whether that be for purely informational purposes or for the purpose of building interpersonal rapport. One of the important and intriguing points that Goffman (1967) makes is that "during a contact of a particular type, an interactant of known or visible attributes can expect to be sustained in a particular face and can feel that it is morally proper that this should be so" (p. 7) and so "a promise to take ritual care of his face is built into the very structure of talk" (p. 40). Such "a promise to take ritual care" of another interlocutor's face involves granting another interlocutor's social identity an adequate level of respect, 
and although norms for the expression of respect differ across cultures ( Argyle et al., 1986), it has been argued that such a desire for respect and the feeling that its presence is morally proper occurs for speakers across all cultures (Brown and Levinson, 1978). In discussing the importance of respect to those growing up and living in the inner city more specifically, Anderson (1999) explains in Code of the Street that by the time most children become teenagers they "have internalized the code of the street" (p. 72) which "revolves around the presentation of self" (p. 72). The following passage from Anderson (1999) is illuminating:

At the heart of the code [of the street] is the issue of respect - loosely defined as being treated "right" or being granted one's "props" (or proper due) or the deference one deserves [...] In the street culture, especially among young people, respect is viewed as almost an external entity, one that is hard-won but easily lost - and so must constantly be guarded. The rules of the code [of the street] in fact provide a framework for negotiating respect. With the right amount of respect, individuals can avoid being bothered in public. This security is important, for if they are bothered, not only may they face physical danger, but they will have been disgraced or "dissed" (disrespected). (p. 33-34)

Respect and positive face have even been characterized as a kind of social currency or "social capital." As it is the case with money, you can get more things done with the more respect and positive face you have. Because these views are important for understanding the linguistic behavior under consideration, I once again provide a passage from Anderson (1999):

In the inner-city environment respect on the street may be viewed as a form of social capital that is very valuable, especially when various other forms of capital have been denied or are unavailable. Not only is it protective; it often forms the core of the person's self esteem, particularly when alternative avenues of self-expression are closed or sensed to be [...] Given its value and its practical implications, respect is fought for and held and challenged as much as honor was in the age of chivalry. (p. 66)

In line with this characterization of respect and positive face as "social capital," I suggest that one might regard (a) directing face threats as directing deductions to the target's social capital, (b) directing face compliments as directing deposits to the target's social capital, (c) receiving face threats as receiving deductions to one's own social capital, and (d) receiving face compliments as receiving deposits to one's own social capital. I further suggest that speakers can, and of ten do, use derogatory language as a linguistic means for the negotiation of social capital in this way. Slurring terms can be understood as affording speakers a linguistic resource with which to recalibrate the organization of their behavior with respect to other group members, facilitating competition, coalition breakdown, or out-group membership (other techniques for initiating face threats might include the absence of polite forms of speech, or the presence of impolite forms, including in some cases the use of imperatives, etc. (Samra-Fredericks, 2010)). Consider the following passage from Code of the Street:

One way to campaign for status is to take the possessions of others. Seemingly ordinary objects can become trophies with symbolic value that far exceeds their monetary worth. Possessing the trophy can symbolize the ability to violate somebody - to "get in his face," to dis him - and thus to enhance one's own worth by stealing someone else's. The trophy does not have to be something material. It can be another person's sense of honor, snatched away with a derogatory remark. (Anderson, 1999, p. 75) 
Furthermore, because "Esteem is so precarious that it can be taken away with just a word, and kids are constantly challenged to defend what they have," it is often the case, Anderson (1999) suggests, that "Social lif e becomes a zero sum scenario" (p. 95). Greene (2011) also writes, in an article for The Economist, about his own experience growing up as a teenager, remarking that one's own "identity is forming with a lot of other identities forming around you. People elbow for status, and often the easiest way to do it is to demean someone else, raising your relative rank just a bit." Based on the accounts provided by Greene, 2011 and Anderson, 1999, I suggest that an intended or unintended consequence of (a)-(d) above is that (a) directing face threats, or directing deductions to the target's social capital, might also serve the function of receiving deposits to one's own social capital, (b) directing face compliments, or directing deposits to the target's social capital, might also serve the function of receiving deductions to one's own social capital, (c) receiving face threats, or receiving deductions to one's own social capital, might also serve the function of conceding deposits to the threat-director's social capital, and (d) receiving face compliments, or receiving deposits to one's own social capital, might also serve the function of conceding deductions to the complimentdirector's social capital.

Notice that both (a) and (d) have the similar effect of increasing the subject's social capital (and thereby decreasing the target's relative social capital) but that (a) offers an active mode of attaining this, whereas (d) offers a passive mode. Presumably, (d) is the more socially acceptable mode, but those on an active "campaign for status" may at times choose (a) instead. Notice also that the other pair (b) and (c) have the effect of decreasing the subject's social capital (and thereby increasing the target's relative social capital) but that (b) offers an active mode of attaining this whereas (c) offers a passive mode. Intuitively, (c) might seem like the most common mode of decreasing one's own social capital, since usually the "campaign" is for status rather than against it, but then again we do often give valuable gif ts to one another to show our respect and affections, so of ten times (b) is a viable mode also. It should be noted, however, that it is unlikely to be the case that all social exchanges involving face threats and face compliments require such a zero-sum analysis. For instance, there is likely to be some cases where a sincere compliment between close friends in fact raises the social capital of both the compliment-giver (if this act of face-complimenting the target makes the compliment-giver appear good for noticing and complimenting the target) and the compliment-receiver (if this act of having one's face complimented makes the compliment-receiver appear good for possessing the feature being noticed and complimented on). There is also likely to be some cases where a face threat in fact lowers the social capital of both the threat-giver (if this act of face-threatening the target makes the threatgiver appear bad or insensitive for directing it) and the threat-receiver (if this act of having one's face threatened makes the threat-receiver appear bad or cowardly for receiving it). Nevertheless, it may be helpful to think of many cases involving face threats and face compliments through a zero-sum framework, as Greene, 2011 and Anderson, 1999 have hinted at, and in these cases it is helpful to think through the various relations pointed out in (a)-(d) above.

As Goffman (1983) discusses in "The Interaction Order," one's face can be considered socio-culturally "f ragile" insofar as it depends upon being continuously co-constituted within the "interactional order" of one's society and culture (Goffman, 1983). So, unsurprisingly, the presentation of self is of ten supported with material objects that help one to establish and maintain their self-image. Anderson (1999) mentions how people gather around designated areas known as "staging areas," to "profile" or display their social face, "“representing" the image of themselves by which they would like to be known: who they are and how they stand in relation to whom" (p. 22). At such staging areas - Anderson (1999) mentions Vernon Park in Philadelphia as an example people of ten showcase expensive clothes, jewelry, or firearms, which reflect both their aesthetic taste and bold willingness to showcase expensive items that might require defending (Anderson, 1999).

When the background conditions of sufficient respect and preservation of face, which are "built into the very structure of our talk" (Goffman, 1967, p. 40), are called into question or challenged, the stability of the social 
identity or face being supported by these conditions is also threatened. Often strong emotional reactions will resultantly be expressed in targets and action on their part will be taken to restore the normative interactional order and salvage face (Goffman, 1967). For example, in "Ethnomethodology and the Moral Accountability of Interaction," Samra-Fredericks (2010) studied the communicative exchanges of business professionals in meetings and found that when one of the subjects had their social position as senior manager challenged, action from both the challenged subject as well as his colleagues was immediately taken to restore the normative interactional order and salvage his face (for more on ethnomethodology see Garf inkel, 1967 and Heritage, 1984). As Samra-Fredericks (2010) reports, "when elusive/taken-for-granted social-moral orders are breached, not only do the backgrounded constitutive expectancies surface, but expression of feelings and displays of emotions also work to 'mark up' the breach and simultaneously warrant the display and invite a response (justification, explanation, etc.)” (p. 2148).

Generally, in situations where one has their identity challenged in this way, the individual working to uphold their identity will resultantly have to choose between (a) loosing their recognition as someone appropriately entitled to that identity (e.g., their identity as a competent senior manager is challenged), or (b) employing strategies, linguistic or otherwise, to counter the original face threat and repair or maintain their face (Goffman, 1967). The choice of (a), while avoiding confrontation, clearly leads to face loss as one is thereby judged to be incompetent with respect to the tasks or actions required of agents assuming the identity in question, whereas (b), while avoiding face loss by standing up for oneself and acting to legitimate their status as a member of the identity in question, clearly leads to confrontation, which is also undesirable but for different (potentially physical) reasons. When deciding what to do in such a situation, an agent must take their preferences into consideration and determine whether in this case they prefer (a) to avoid confrontation and loose face, or (b) to avoid losing face by responding confrontationally.

Brown and Levinson (1978) have also explained that when a speaker S strategically indicates through their use of language that they are more powerful or of a higher social status than their hearer $\mathrm{H}$, they can of ten be understood as acting confrontationally, which may be risky. However, if S nonetheless gets away with the confrontational linguistic act, and $\mathrm{H}$ for whatever reason does not retaliate, "S [thereby] succeeds in actually altering the public definition of his relationship to $\mathrm{H}$ : that is, his successful exploitation becomes part of the history of interaction, and thereby alters the agreed values of $D$ [social distance between $S$ and $H$ ] or $P$ [relative power between S and H]" (Brown and Levinson, 1978, p. 228). Social distance typically refers to the symmetrical notions of social similarity and familiarity whereas social power typically refers to the asymmetrical notions of differences in relative social rank and relative social control (Nevala, 2004). Further, it has been noted by scholars that for most Americans power typically implies distance whereas solidarity typically implies closeness ( Tannen, 1993, p. 26). Since it has been previously argued that shows of deference from others can make one feel a sense of self-confidence and security, this might serve as one reason for why a speaker $\mathrm{S}$ might be motivated to strategically indicate through their use of language that they are more powerful or of a higher social status than their hearer H (Anderson, 1999, p. 75). On the other hand, since it has been previously argued that as a person's "reputation becomes sullied" they become "increasingly discredited as a full person in the community" ( Anderson, 1999, p. 216), this might serve as one reason for why a hearer $\mathrm{H}$ might be motivated to strategically indicate through their use of language that they are not less powerful or of a lower social status than the speaker $\mathrm{S}$.

Finally, before moving on, it may be useful to note that although women and men sometimes initiate conflicts for different reasons - for instance Anderson (1999) suggests that the former dispute more over evaluations of beauty and that the later dispute more over status and turf (p.63) - teenage girls and young women, much like teenage boys and young men, also of ten compete in social contests to gain respect and use posturing and abusive language in order to accomplish this. As Anderson (1999) explains, "a major cause of conflicts among girls is "he say, she say," particularly those involving issues of personal attribution, or name calling," which is a "practice [that] begins in the early school years and continues through high school" (p. 64). It stands to reason then that since our social identities are in part determined by the way members of society perceive 
us, and so the way members of society interact and continue to interact with us (Goffman, 1967 and Brown and Levinson, 1978), the derogative use of racial and sexist slurs, for example, can be extremely destructive to the actual character of the individuals that they attack. A speaker that derogates someone on the basis of negatively perceived features through their use of a racial or sexist slur might thereby enforce, support, and contribute to a history of derogatory or dehumanizing acts that harm the social identity of the members that are typically targeted. Presumably this is done for the purpose of increasing the difference in asymmetrical power relations among the interlocutors involved in the particular conversational context, or among the social groups to which they belong more generally (Croom, 2011). In order to understand how racial slurs in particular might be used for the purpose of increasing the difference in asymmetrical power relations among the social groups to which the speaker and hearer belong, it will be instructive to first briefly discuss the process of social stratification and the basis for out-group derogation. Since we have also previously mentioned the notion of social identity in passing, at this point it would be apt to further unpack this notion in some detail.

\section{Social stratification and the basis for out-group derogation}

According to scholars, the institution of slavery has carried on for approximately ten thousand years, emerging as the discovery of agriculture enabled nomadic tribes to settle, till the soil, and domesticate wild plants and animals (Smith, 2011). As people began to settle and permanently anchored themselves to sections of land, the accumulation of land and property became increasingly important resources, leading to the development of systems of proprietary ownership, divisions of labor, and social stratification. Resultantly, as production and population density increased, settlements expanded into larger towns and cities, and what had before been a more egalitarian hunter-gather style of living had been replaced by a more socially hierarchical one (Smith, 2011). A consequence of the resulting social hierarchies, evidently, is that some members will be regarded with relatively higher social standing than others that will be regarded with relatively lower social standing.

This process of social stratification involves the demarcation of social groups (Erikson, 1986), and it is now well known that those from the upper, middle, and lower class identify themselves as members of their respective classes through cultural markers, such as clothing styles, cultural rituals, and forms of speech that distinguish them from others (Smith, 2011). The importance of maintaining the cultural and intellectual independence of one's own social group has often been advocated by numerous figures, including for example W. E. B. Du Bois, Malcolm X, Elijah Muhammad, Richard Wright, Marcus Garvey, Huey Newton, Leonard Jeffries, Molefi Asanti, Ron Karenga, Louis Farrakhan, and many others. As these and other individuals have argued, one's status as an African American, for instance, reflects their own unique and important sense of history, culture, and identity (Dawson, 2001 and Sniderman and Piazza, 2002). This view is also reflected in the popular opinion of African Americans, with a study by Sniderman and Piazza (2002) showing that the majority of their respondents "have a distinct sense of being black, of belonging to a distinctively black culture, and of taking pride in both" (p. 177). Sniderman and Piazza (2002) also found that racial identif ication typically expresses itself in various ways, including but not limited to (a) "feeling a sense of identity and distinctiveness as a black in America" (p. 158); (b) "in insisting on the need to overcome the injustices of the past" (p. 158); (c) "in taking pride in the history blacks share and the works of all kinds they have accomplished" (p. 158); (d) "in wanting to promote an independent role for blacks to play as blacks and on behalf of blacks" (p. 158); (e) "in insisting on recognition of achievement of fellow blacks" (p. 158); and (f) "the desire of black Americans to exercise a greater measure of control over their future [..., for example,] that black Americans should have control over the economy in mostly black neighborhoods and that blacks should shop in stores owned by other blacks whenever possible" (p. 161). As Sniderman and Piazza (2002) summarize from their large scale statistical analysis of the reported beliefs of African Americans in Black Pride and Black Prejudice:

there is no question that black Americans have a sense of forming a distinct body of people, sharing a history of suffering and accomplishment that gives them a unique identity and perspective. And an integral element of this sense of collective identity is a belief that the interests and prospects of 
blacks not just as individuals, but as black Americans, are and ought to be the object of concern [... This is because] the criterion of feeling a sense of racial solidarity [... involves] a belief in genuine interconnectedness, a sense of a direct connection between other blacks and oneself, so that what happens to other blacks bears on what happens to one as a black. So conceived, a feeling of racial solidarity centers on a conviction that black Americans, by virtue of being black in America, share a common fate. (pp. 160-161)

In addition to one's particular styles of clothing, tattooing, and other cultural rituals, one's "prototypical speech habits" are also an especially salient marker of social identity and group membership (Anderson, 2008, p. 122, 118; see also Johnstone, 1995). "The rap is the verbal element," Anderson (1999) explains in Code of the Street, and "It embodies the whole person" (p. 151). Af rican American Vernacular English (AAVE), for instance, refers to a vernacular form spoken primarily by working-class African Americans, and has been argued to be markedly distinct from any other European American vernacular ( Wolf ram, 1974; Bailey, 2001 and Thomas, 2007). Linguistic studies have found numerous morphological and syntactic features that function as salient markers of AAVE ( Fasold, 1981), some of which include (1) invariant be (e.g., we be cooking tonight); (2) copula deletion (e.g., we cooking tonight); (3) third-person singular -s absence (e.g., he think he got game); and (4) replacement of didn't with ain't (e.g., I ain't hit the gym yet).

Other features distinguishing AAVE from other vernacular forms include prosodic, vocalic, and consonantal variation, as well as variation in voice quality (Thomas, 2007). Some of these features that have been suggested by linguistic studies include (5) higher rates of non-rhoticity, or $r$-less-ness, among Af rican Americans than European American cohorts ( Labov et al., 1968, Williamson, 1968, Wolf ram, 1969, Foley, 1972, Baugh, 1983, Pederson et al., 1986-1992, Myhill, 1988, Edwards, 1997 and Wolf ram and Thomas, 2002); (6) substitution of /skr/ for /str/ ( Fasold and Wolfram, 1970, Labov, 1972a, Wolfram and Fasold, 1974, Bailey and Thomas, 1998, Bailey, 2001 and Wolf ram and Thomas, 2002); (7) higher rates of "broad a" (e.g., as in aunt with the vowel of LOT instead of with the vowel of TRAP); (8) monophthongization, or weakening of glides of the mouth vowel (Wolfram and Thomas, 2002 and Thomas, 2007); (9) a shift of word stress to the first syllable in words that are stressed on other syllables in other vernacular forms (e.g., as in December, July, police, hotel) ( Fasold and Wolfram, 1970 and Baugh, 1983); (10) the use of a wide pitch range, realized as expansions into higher pitches, especially in competitive style speech events ( Tarone, 1973, Loman, 1975, Hudson and Holbrook, 1981 and Hudson and Holbrook, 1982; Jun and Foreman, 1996); (11) a greater likelihood of displaying a high tone at the beginning of a sentence, either as a boundary tone or as a high initial pitch accent, i.e., pitch prominence; (12) a greater likelihood of displaying a variety of final contours in yes/no questions, such as falling or level final contours (Green, 2002), whereas European Americans consistently show a rising final contour ( Jun and Foreman, 1996); (13) a statistically significant tendency to raise fundamental frequency (F0) from one stressed syllable to the next more of ten than European Americans ( Wolf ram and Thomas, 2002); (14) the deletion of final /n/, with only nasality on the preceding vowel remaining ( Bailey, 2001); (15) the deletion of morpheme final voiced stops ( Thomas, 2007); (16) the deletion of nasals in non-final contexts ( Thomas, 2007); and (17) devoicing, of ten accompanied by glottalization, of morphemefinal $/ \mathrm{d} / \mathrm{g} / \mathrm{g} /$, and $/ \mathrm{b} /$.

Additionally, linguistic studies have also found that (18) Af rican Americans displayed greater local F0 variation (jitter) and local amplitude variation (shimmer) than European Americans (Walton and Orlikoff, 1994); (19) Af rican American men exhibited a greater F0 range within stress feet and lower minimum and overall F0 values than European American cohorts (Hollien and Malcik, 1962, Hudson and Holbrook, 1981, Hawkins, 1993, Walton and Orlikoff, 1994 and Cole et al., 2008); (20) African Americans exhibit a lower degree of nasality than European Americans (Thomas, 2007); and (21) Af rican American men exhibit more "breathiness" and less "creakiness" in their speech than European American men (Thomas and Reaser, 2004). Further, although speakers of many dialects will tend to simplify consonant clusters and delete a stop when the following word begins with a consonant (e.g., as in pas' the house), (22) deletion of a stop when the following word begins 
with a vowel (e.g., as in pas' a house) occurs more frequently in AAVE than any other European American dialect at any social level ( Labov et al., 1968, Wolfram, 1969, Fasold and Wolf ram, 1970, Labov, 1972a, Baugh, 1983, Miller, 1986, Butters and Nix, 1986, Pederson et al., 1986-1992, Gordon, 2000 and Wolfram and Thomas,

2002).

It has been argued that these morphological and syntactic features salient in and characteristic of AAVE not only distinguish it from other European American vernaculars, but further distinguish it from Af rican American English (AAE), which refers to "the speech of all Af rican Americans, including middle-class African Americans" (Thomas, 2007, p. 451). Typically, AAE lacks the aforementioned morphological and syntactic features (1)-(4) (invariant be, copula deletion, third-person singular $-s$ absence, and replacement of didn't with ain't) that are distinctive of AAVE, as these features have become stigmatized ( Thomas, 2007). These features have become stigmatized, presumably, by virtue of the fact that they are most typically displayed in the speech of, and so most characteristically associated with the speech of, the vernacular form spoken principally by those being regarded as the lower working class (who in this case happen to be African American). That is, as those of a higher class than the working-class would want to indicate their higher status to others, one way of doing this would be to avoid using the speech patterns associated with those members of the lower class. In so doing, one could be strategically signaling that they are not part of the low-status culture of the working class and the speech patterns principally spoken by those that are members of that (lowly) in-group.

For instance, work in sociolinguistics has found that the rate of $r$-less-ness between interlocutors also decreases as their social level increases and their speaking style becomes more formal ( Thomas, 2007). In a study of AAE in New York City, Labov et al. (1968) found that substitutions for /ð/ were more common than those for $/ \theta /$ and that the frequency of substitutions were inversely correlated with social class and formality of speaking style. In another study of AAE in Detroit, Wolf ram (1969) showed that devoicing and deletion of morpheme-final/d/ became more typical as socioeconomic level decreased, and that substitutions for $/ \theta /$ were less common among higher social levels, females, and speakers with extensive contact with whites, and more common among lower social levels, males, and speakers with limited contact with whites. In yet another study in Wilmington, North Carolina, Butters and Nix (1986) found an inverse relationship between / $\theta /$ substitutions and social class. Finally, Pederson et al. (1986-1992) also found that feature (9) above - that is, the shift of word stress to the first syllable in words that are of ten stressed on other syllables - which had been identif ied as a marker of AAVE, was also more common among speakers of lower social levels.

We should not, after all, be surprised that language is used at least in part to mark social identities, bringing us closer to some groups of people and distancing ourselves from yet others. It is worth emphasizing at the moment, before pressing on, the importance and historical endurance of using forms of speech as a marker of social identity. For instance, the following passage from the Book of Judges makes the point about language as a marker of social identity especially clear:

Whenever a survivor of Ephraim said, "Let me cross over," the men of Gilead asked him, "Are you an Ephraimite?" If he replied, "No," they said, "All right, say 'Shibboleth." He said, "Sibboleth," because he could not pronounce the word correctly, they seized him and killed him at the fords of the Jordan. Forty-two thousand Ephraimites were killed at that time. (Judges 12:5-6)

A comparison with the Greeks may also be helpful at this point, for the Greeks of Aristotle's era also considered speech to be of central importance in marking, not only one's social identity, but their very status as a human being. As Strabo the Greek has written, Greeks regarded foreign non-Greeks as barbaroi- "the bar bar people" or "barbarians" - because they produced sounds like "bar, bar" instead of sounds that were familiar to the Greeks as intelligible speech. Further, it has been argued that because the Greeks considered themselves paragons of civilization, and so considered their language to be superior to the language of 
others, the Greeks used a person's ability to speak their own language as a criterion for assessing their status as a fully rational, and so fully human, being. Heath (2005) seems to be expressing this point in saying that the barbarian other "is primarily language deficient [...] The close connection between speech and reason made it easy to assume that barbaroi - like slaves (and animals, I would add) - lacked both. With the loss of speech and reason, foreigners were in danger of losing all of their humanity" (p. 201). Jacoby (1994) has likewise argued that since "the ability to communicate through speech is one of the most commonly made distinctions between humans and animals [...] the captive's lack of intelligible speech [...] most likely made them appear less than fully human" (p. 92-94), and so contributed towards their dehumanization ( Smith, 2011). The point is that by referring to targets with terms publically known to be reserved for derogation instead of referring to targets with terms publically known to be reserved for friends, peers, or other equals, Greek speakers could attempt to sidestep or avoid thinking of the "barbarians" in the same terms as other equal (Greek) human beings and so could more easily treat them in ways that were inferior and subhuman.

Thus, since it was commonly thought that the barbarians had only rudimentary linguistic and reasoning abilities, and since it was also thought through Aristotle's influence that it is precisely these abilities that make one essentially human, the Greeks concluded that any being (any barbarian "other") deficient in linguistic and reasoning abilities are thereby also deficient in their status as a fully human being (Shields, 2007). Scholars have suggested that those that did not participate in Greek life, culture, and language were considered outgroup members by the Greeks, and were generally regarded as subhuman. And since the barbarian other did not participate in Greek life, culture, and language, the Greeks therefore held that they did not properly belong to the civilized life of the polis, and so must act - must be made to act, even - in subservience to their fully rational, and so fully human, Greek masters ( Smith, 2011, p. 31-35).

\section{Slurs I: the paradigmatic derogatory use of slurs}

This biased psychological tendency to believe that one's own language is superior to that of all other foreigners, and that foreigners are cognitively unequipped to proficiently speak one's own language, has actually been a noted feature of those with xenophobia, which is characterized as a "fear and hatred of strangers or foreigners or of anything that is strange or foreign" (Merriam-Webster, 2010). Also, the psychological basis underwriting differential behavior toward group and non-group members may not be peculiar to humans alone, but also seems present in other non-human primates, such as chimpanzees, suggesting that the psychology involved in such differential behavior is not merely a cultural peculiarity but has roots in the evolved architecture of the human mind (Goodall, 2000 and Smith, 2011).

Yet despite the possible cultural and evolutionary basis for the origins of dehumanization, it has been argued that the institution of slavery nonetheless brought along with it a disturbing moral issue for many slave owners. This moral issue focused on how to reconcile the conflict between the economic attractions to be gained from slavery on the one hand, and the Enlightenment vision of human dignity on the other. Jacoby (1994) has previously outlined the dilemma in noting that the institution of slavery was one that "treated humans like domestic animals" despite the fact that it was clear that "humans and livestock were not the same," so the "easiest solution" for slave owners having to deal with their own behavior towards their slaves, "was to invent a lesser category of humans [with which to identify their slaves] that supposedly differed little from brute beasts" (pp. 92-94). Indeed, Rahman (2012) has argued that "Before the nineteenth century, Af ricans did not count as humans" (p. 143), Herbert (2003) claims that it was thought that "Blacks were congenitally unf it for civil society and, therefore, its freedoms" (p. 166), and Anderson (1999) has argued that "In the days of slavery and then of sharecropping, when black men generally were unable to achieve economic independence [...] The black man was frequently, but not always, emasculated, weakened, or simply neutralized by the social control efforts of the wider white society, and was thus reduced as a competitive force in a maledominated society" (p. 207; see also Taslitz, 2000). Therefore, it is unfortunate yet clear that many slave owners had a motivation for considering Africans as subhuman beings, for if Africans could be considered merely subhuman then slave owners could escape feeling morally obligated to treat them with genuinely 
humane considerations altogether.

One example of the way that slaves were dehumanized was through objectification, that is, through being treated purely instrumentally as a tool or commodity to be traded, bought, or sold (Dworkin, 2000). That slaves were often treated as nothing more than work equipment is conveyed through some of the names that they were called. For instance, African American slaves were of ten referred to as "antique farm equipment" (Croom, 2008, pp. 34-45). When this form of objectification occurs, as Dworkin (2000) explains, "a human being, through social means, is made less than human [...] so that no individuality or integrity is available socially [...] those who can be used as if they are not fully human are no longer fully human in social terms; their humanity is hurt by being diminished" (pp. 30-31). In fact, Patterson (1985) has argued that the defining characteristic of slavery is social death, that is, by the slave being considered and treated as a nonperson (p. 24). For instance, planters in the North American and British Caribbean colonies prevented slaves from being baptized and receiving religious instruction (Smith, 2011). So it is very likely that foreigners were dehumanized before being enslaved, and that slavery then acted to reinforce their subhuman status ( Smith, 2011). In short, it has been argued that by dehumanizing others either verbally or physically, one acts to disarm people's inhibitions against treating them cruelly, and enables people to perform destructive actions against other humans, such as rape and murder, that they would otherwise find unthinkable (Chandler, 1999 and Smith, 2011). "As Southerners well understood," Taslitz (2000) suggests, "the purpose of the violence was not solely to discipline the slaves, but also to venerate the owner. The honor of the white man depended upon his lordship over the black man. That lordship required violence so that slaves understood that they could have no world of their own" (p. 1287). Yet it is important to notice, as Delgado (1991) explains, that the perpetuation of race-based dehumanization extended beyond mere physical violence to include an "interlocking series of acts, some physical, [and] some symbolic," such as lynching and slurring, respectively, and that even though "the physical acts (like lynching and crossing burnings) are of ten the most striking, the symbolic acts are the most insidious" (p. 374, my emphasis).

Delgado (1991) argues that the symbolic acts expressed through pictorial images and derogatory language are often the most striking because in "communicating and "constructing" a shared cultural image of the victim group as inferior, we enable ourselves to feel comfortable about the disparity in power and resources between ourselves and the stigmatized group" (p. 374). It is unsurprising, then, that propaganda and mass media have been largely responsible for the perpetuation of race-based dehumanization, including the propagation of dehumanizing stereotypes (Bonnell, 1998 and Smith, 2011). As a case in point, literature published during the latter part of the nineteenth and early twentieth centuries continued to advance claims to the effect that Af rican Americans were subhuman beasts (Smith, 2011). Aldous Huxley further argues that the very aim of propaganda is to dehumanize others:

Most people would hesitate to torture or kill a human being like themselves. But when that human being is spoken of as though he were not a human being, but as the representative of some wicked principle, we lose our scruples [...] All political and nationalist propaganda aims at only one thing; to persuade one set of people that another set of people are not really human and that it is therefore legitimate to rob, swindle, bully, and even murder them. (quoted in Lifton and Humphrey, 1984, $p$. 10)

Yet race-based dehumanization has also been perpetuated through more direct linguistic interaction, including the practice of referring to slaves as animals or tools and targeting them with racial slurs (Croom, 2011 and Croom, 2012b). Af rican Americans that have been derogated with the slur nigger have typically been derogated on the basis of being "emotionally shallow, simple-minded, sexually licentious, and prone to laziness" ( Asim, 2007, p. 27), and so it is in such contexts where a speaker intends to ascribe at least some such features to a target that the slur nigger has typically been employed. We can reasonably call this the paradigmatic derogatory use of slurs. By referring to targets with terms publically known to be reserved for 
derogation instead of referring to targets with terms publically known to be reserved for friends, peers, or other equals, racist speakers could attempt to sidestep or avoid thinking of their targets in the same terms as other equal human beings and so could more easily treat them in ways that were inferior and subhuman.

Thus, the use of derogatory language, including the use of racial slurs, is thought to have played an instrumental role in the perpetuation of race-based discrimination because slurring terms offered racist speakers a linguistic resource with which to dehumanize their targets and identify them in "subhuman," rather than fully human, terms. Scholars have previously mentioned, for instance, that "the British and their colonial counterparts relied on [derogatory] language to maximize the idea of difference between themselves and their Af rican captives" (Asim, 2007, p. 12) which amounted to "an articulate and aggressive racism which excluded the Negro from the society of competing equals without deporting him, by the simple and brutal mechanism of formally defining him as subhuman" (Fredrickson, 1971 and Croom, 2011). Finally, Blassingame (1979) famously noted in The Slave Community that "The idea of the superiority of whites was etched into the slave's consciousness by the lash and the ritual respect he was forced to give to every white man," and that "to relieve themselves of the anxiety of thinking about slaves as men [...] whites of all classes came to rely on language (and especially the use of pejoratives like the N word) in the pursuit of such relief" (p. 14). (One is also reminded by this discussion of the following exchange between Sally and Huckleberry Finn in Chapter 32 of Twain's (1986)The Adventures of Huckleberry Finn: [Sally:] "Good gracious! Anybody hurt?" [Huckleberry Finn:] "No'm. Killed a nigger." [Sally:] "Well, it's lucky; because sometimes people do get hurt.")

In this section we have looked in some detail at the paradigmatic derogatory use of racial slurs, focusing on the slur nigger in particular, and have also considered its origins, history, and contexts of use. Accordingly, in the next section we will consider another use of slurs, which can reasonably be called the non-paradigmatic derogatory use of slurs.

\section{Slurs II: the non-paradigmatic derogatory use of slurs}

It was discussed in the previous section that African Americans that have been derogated with the slur nigger have typically been derogated on the basis of being "emotionally shallow, simple-minded, sexually licentious, and prone to laziness" ( Asim, 2007, p. 27), and that resultantly, it is in such contexts where a speaker intends to ascribe at least some such features to a target that the slur nigger has typically been employed. These cases were instances of the paradigmatic derogatory use of slurs. Yet, interestingly enough, slurs are of ten used in a non-paradigmatic way to dehumanize targets that are not typically associated with the original slur. For example, in his national bestseller All Souls: A Family Story from Southie, MacDonald (2000) discusses how slurs were used in his linguistic community and reports that in certain cases the racial slur nigger was felicitously ascribed to non-African American individuals. According to MacDonald (2000):

\footnotetext{
Danny told me that the people that ended up in D Street were "white niggers" [...] Of course, no one considered himself a nigger. It was always something you called someone who could be considered anything less than you. I soon found out that there were a few black families living in Old Colony. They'd lived there for years and everyone said that they were okay, that they weren't niggers but just black. (pp. 60-61)
}

Similarly, in his standup performance Chewed Up (2008), Louis Szekely (a.k.a. Louis C.K.) discusses how slurs were used in his linguistic community and reports that in certain cases the sexist slur faggot was felicitously ascribed to non-homosexual individuals ( Szekely, 2008, "Offensive Words"). According to Szekely (2008): 
know? [...] "you're not supposed to use those for that" [said in an annoying mocking voice as if from another person, then Louis C.K. replies normally] "shut up faggot!" [...] I would never call a gay guy a faggot, unless he was being a faggot. But not because he's gay, you understand. ("Offensive Words")

It therefore seems evident from the examples above that, even if the majority or most salient cases of slurring might involve instances of the paradigmatic derogatory use of slurs, the paradigmatic derogatory use of slurs is not the only use of slurs. Rather, the examples above suggest a second kind of use for slurs, which can reasonably be called the non-paradigmatic derogatory use of slurs. That is, it is evident from examples like those above that there are meaningf ul and felicitous uses of racial slurs that need not target an individual belonging to the race typically associated with that racial slur (e.g., MacDonald, 2000), and that there are meaningf ul and felicitous uses of sexist slurs that need not target an individual belonging to the sexual group typically associated with that sexist slur (e.g., Szekely, 2008). The purpose of Section 11 will be to explain how a family-resemblance conception of category membership can help us achieve a clearer understanding of the various ways in which slurs are actually used in natural language discourse, including (a) the paradigmatic derogatory use of slurs, (b) the non-paradigmatic derogatory use of slurs, and (c) the non-derogatory ingroup use of slurs. But before proceeding to do so, I will first discuss the third and last kind of use of slurs to be considered in the present work, (c) the non-derogatory in-group use.

\section{Slurs III: the non-derogatory in-group use of slurs}

Recently, several scholars have called attention to the fact that slurs are not always or exclusively used to derogate. In fact, slurs are frequently picked up or appropriated by the very in-group members that the slur was originally intended to target, presumably as a means for like speakers to strengthen in-group solidarity (Kennedy, 2002, Brontsema, 2004, Croom, 2010b, Croom, 2011, Croom, 2012b and Cameron, 2012a), and scholars have noted that the nonpejorative variant of the racial slur nigger, for instance has been around since at least the early 1800s ( Dillard, 1977, Stuckey, 1994, Spears, 1998, Jacobs, 2001, Wilson, 2002 and Rahman, 2012). The appropriative use of slurs - or what I call here the non-derogatory in-group use of slurs - is a bone fide and widespread use of slurs that carries with it a positive, non-pejorative meaning or signif icance when used by in-group speakers that differs markedly from the "Pejorative meanings that have historically come from outside the community" ( Rahman, 2012, p. 141). This markedly different use of the slur is, at first blush, puzzling. For the question naturally arises: how can slurs, which have historically been used for derogation, be used by certain speakers for building rapport when derogating targets and building rapport with targets are thought to be diametrically opposed? Indeed, some that reject in-group uses of slurs are usually concerned that their use is somehow symptomatic of the internalization of white racism (Kennedy, 2002, Asim, 2007 and Rahman, 2012). The idea is that since uses of racial slurs have, historically, of ten been accompanied by physical violence ( Butler, 1997, Coupland, 2007 and Zizek, 2007), the derogatory force behind uses of slurs remains an active part of public consciousness. So some scholars have thus argued that the derogatory force associated with the term disallows the legitimacy of positive in-group uses among, for instance, fellow African Americans (Kennedy, 2002, Larkins, 2006, Asim, 2007 and Rahman, 2012).

Yet others scholars, as well as many every day speakers, find this view largely outdated and unpersuasive, pointing to the evident fact that slurs are frequently picked up or appropriated by the very in-group members that the slur was originally intended to target. For instance, Kennedy (2002) asserts that African Americans continue to use the slur "openly and frequently in conversations with one another" (p. 37), and Spears (1998) argues that "the great majority of African Americans, male and female, use $\mathrm{N}$ [i.e., the N-word nigger] when among other African Americans, and do so regardless of their attitudes about $\mathrm{N}$-use. In other words, some may be against $\mathrm{N}$-use, but use it nevertheless" (p. 239). In one study a thirty-seven-year-old interviewee also remarks that, "You see, the people who say they're offended are the older adults. Young kids don't understand what the big deal is about the word. They know it's about black people and slavery, but they're like 'that's over'” 
(quoted in Rahman, 2012, p. 161). This markedly different in-group use of the slur will become less puzzling once we understand it in its proper context, so the aim of the present section will be to discuss the nonderogatory in-group use of slurs and the contexts in which they occur.

First, it has been pointed out that the non-derogatory in-group use of slurs is especially prevalent in communities highly influenced by "counterculture" norms (i.e., norms adopted in opposition to, and for the purpose of subverting, other entrenched sociocultural norms that a group contests), such as those associated with hip-hop culture. For instance, Cutler (2009) has pointed out that within hip-hop culture, "Whiteness is marked against a backdrop of normative Blackness" (p. 80; see also Boyd, 2002, Alim, 2006, Lee, 2009a and Lee, 2009b). A reason for this normative reversal, from a backdrop of normative Whiteness to a backdrop of normative Blackness, can be gleaned from a passage in Anderson's (1999)Code of the Street:

[In the inner city,] the despair, the alienation, and the distress are still there, and this condition encourages the development and spread of the oppositional culture [...] In this scenario, anything associated with conventional white society is seen as square; the hip things are at odds with it. The untied sneakers, the pants worn well below the waist, the hat turned backward - all have become a style. These unconventional symbols have been taken over by people who have made them into status symbols, but they are status symbols to the extent that they go against what is conventional [... people embracing the oppositional culture] take heart from professional athletes who confront the system and stand up for themselves. In their view, policemen, public officials, and corporate heads are unworthy of respect and hold little moral authority [...] A counterculture thus emerges, with the purpose of making a cultural statement against a dominate society that many young innercity blacks feel disrespects them. (p. 112, 36, 234)

Thus, because many inner-city residents feel that the wider system has abandoned them and disrespects them, they often find it important to distinguish their appearance and behavior with a marked unconventionality, of ten influenced by the oppositional norms of the inner city culture (Anderson, 1999). Inner-city residents that find it important to distinguish their appearance and behavior with a marked unconventionality, unsurprisingly, of ten find it important to distinguish their speech styles and strategies also. Interestingly, one of these strategies involves subverting derogation through linguistic appropriation such that between in-group speakers the slur is used as a norm reversed variant of the original derogatory use, and thus understood between ingroup speakers as intended non-derogatorily. For instance, the hip-hop artist Talib Kweli claims that, "Our community has been using the word and trying to redefine the context of it for a long time. And a lot of people make the argument that it's destructive. And it is - in a lot of ways. But the fact of the matter is that there's a large segment of black people who grew up hearing the word intended as nothing but love" (quoted in Echegoyen, 2006). Russell Simmons, founder of Def Jam Records, also claims that:

When we say 'nigger' now, it's very positive. Now all white kids who buy into hip-hop culture call each other 'nigger' because they have no history with the word other than something positive [...] When black kids call each other 'a real nigger' or 'my nigger,' it means you walk a certain way [...] have your own culture that you invent so you don't have to buy into the US culture that you're not really a part of. It means we're special. We have our own language. (quoted in Jackson, 2005)

Rahman (2012) argues that, "Nigga may [...] serve illocutionary functions related to showing approval or a proactive self-empowerment" (p. 141), Eddie Griffin (2003) advises the audience in the Last Stand to "Be proud to be a nigga. Don't forget. Be a nigga to the heart," and the comedian Katt Williams (2008) further claims that: 
Niggas is an American success story. They can't talk me out of my love for niggas. Niggas is the shit. Niggas went from being treated like dogs til now. That's why I keep sayin the word nigga. Cause I want him to remember what the fuck he came from [...] I'm proud of niggas. Niggas don't never quit. Niggas always come through the motherfuckin trouble - and looking better at the same time. They can't make me feel bad about niggas.

The comedian Freeze Love, who describes himself as a "no limit nigga," explains that, "When I say 'nigga,' I'm talkin' about having game" (quoted in Rahman, 2012, p. 160), which refers to the possession of "a style of carrying and expressing oneself that enables one to achieve a desired end" (Smitherman, 2000, p. 141). Other prominent African American entertainers, such as Richard Pryor (Jackson, 2005), Nas (McLaughlin, 2008), Dave Chappelle (Leung, 2004), Ice Cube, and 50 Cent have also stated that their use of slurs were not intended nor typically understood as derogatory (Croom, 2011 and Cameron, 2012b). Even outside the entertainment circuit, the scholar Henry Louis Gates, Jr., a professor and director of the W.E.B. Du Bois Institute for African American Research at Harvard University, claims that he is not at all offended by the use of the slur in an in-group context among African Americans (Gates, 2009). One thirty-two-year-old male interviewee reported that, "The hip-hop use of nigga represents a growing consciousness of African Americans as subjects rather than objects" and that "I'm my own person" (quoted in Rahman, 2012, p. 159), with Rahman (2012) arguing that the in-group use highlights the in-group member's identity as "African Americans [that] see themselves as resourceful, pragmatic survivors” (p. 159, see also Rahman, 2004 and Rahman, 2007). Rahman (2012) further suggests that, "in a pragmatic instance of appropriation and reanalysis of racist meanings, young African Americans took ownership of the racist form of nigger, turning it to their own use as the nigga form" (p. 159) and that "That's my nigga" [is understood as] Describing the type of close, supportive friendship where use of "my nigga" is appropriate" (p. 155).

It is therefore evident that slurs are of ten exchanged between friends or in-group members, or used in jokes and comedic acts, in a manner that teases, calls into question, and pokes fun at social circles and institutions that actually believe that racist thoughts and actions are worthy of any legitimacy at all. As Rahman (2012) writes in "The N Word, Its History and Use in the African American Community," "through the counter language [i.e., the non-derogatory in-group use of slurs], slaves were known to have covertly mimicked and ridiculed the slave master in his presence" (p. 147; see also Cowan, 2001). Leech (1983) has further argued that interlocutors of ten engage in acts understood to be superficially impolite for the purpose of facilitating social intimacy and equality, and Culpeper (1996) has reinforced this point by arguing that the more intimate a relationship is between two interlocutors, "the less necessary and important politeness is [... Since] lack of politeness is associated with intimacy [...] being superficially impolite can promote intimacy [... however] this only works in contexts in which the impoliteness is understood to be untrue" (p. 352), such as in communicative exchanges between members of the same racial in-group, or between close friends.

Goffman (1967) has also previously pointed out that interlocutors that are on "familiar terms with one another and [so] need stand on little ceremony" are thereby freed to exchange mock insults and jokes in a nonthreatening way "as a means of poking fun at social circles where the ritual [insult] is seriously employed" (p. 86). As an example, consider a speaker $A$, and a hearer $B$, that belong to the same racial group. Imagine that $A$ and $B$ are close friends that are comfortable with each other and at least somewhat familiar with each other's past, general dispositions, and beliefs. Now, if $B$ is familiar enough with A to believe that $A$ is generally a decent, non-racist person, and it is common knowledge between $A$ and $B$ that as a friend $A$ generally intends to create rapport with $B$, then it is more likely to be safe for $B$ to assume prima facie that $A$ meant to create rapport with $B$ rather than to derogate $B$ by A's particular use of the slur. This is, in fact, how one generally creates and maintains friendships, and presumably how $A$ and $B$ in particular became friends in the first place (Croom, 2011). Indeed, it has been argued that $B$ will tend to interpret a possible insult from $A$ as mere banter if $B$ thinks that A generally likes $B$, because the more one interlocutor likes another the more likely it is that the former will 
be concerned with the latter's face and so be cautious not to offend them (Culpeper, 1996). So, for instance, if two African American interlocutors both feel that they share a common history or culture and both understand that neither of them have any intention of offending the other (e.g., they both presume to be on good terms with each other), one of the interlocutors may strategically choose to produce an utterance involving the relevant slur in order to foster intimacy and in-group solidarity; "The solidarity meaning for nigga emerges through common understandings and shared experiences related to survival," as Rahman argues (2012, p. 155). In line with this, Pfister (2010) has also suggested that, "what may seem to be impolite at a (superficial) level of what is said, may nevertheless be polite at a (deeper) level of what is implicated" (p. 1278).

Accordingly, at least in such in-group uses, a slur can be used as a form of "mock impoliteness" since it is understood as intentionally non-offensive (for further discussion of mock impoliteness see Culpeper, 1996). This is presumably made possible by the fact that in-group racial members share in many of the same discriminatory problems and face many of the same discriminatory prejudices, which are "common community experiences [...] that also lead to empathy with fellow African Americans who share in these perceptions and experiences" (Rahman, 2012, p. 155). This might serve as a means for like speakers to foster a sense of solidarity, namely, by being in on this in-group use of the slur. Just as young boys and men rough-house, play fight, and exchange "ritual punches" with each other as friends ( Anderson, 1999, p. 82), they may also verbally "rough-house" with each other as a masculine, status-safe way of showing rapport towards one another. Thus, by creating a sense of solidarity through in-group uses of slurs - the use of which is of ten restricted to only in-group members - speakers are afforded an additional linguistic technique for signaling to each other that they are not alone and that others like them share in their pains, perspectives, and history of prejudices. Sally (2003) argues that speakers engage in this kind of "risky speech" in order "to reinforce their solidarity and rapport [by] us [ing] common ground not so much for translation as for security and assurance" (1237; see also Clark, 2011), and Brown and Levinson suggest that this is how "we get conventionalized (ritualized) insults as a mechanism for stressing solidarity" (1978, p. 229). A large body of literature further supports these

suggestions, showing that narrower psychological and social distance among interlocutors is correlated with a greater use of sarcasm ( Jorgensen, 1996 and Kreuz et al., 1999), banter ( Leech, 1983), teasing ( Drew, 1987), mock impoliteness ( Culpeper, 1996), swearing ( Jay and Janschewitz, 2008), and insults ( Labov,

1972b and Slugoski and Turnbull, 1988). Indeed, 54\% of respondents in a recent Associated Press-MTV study involving 1,355 participants "think it's OK to use them [slurs] within their own circle of friends, because [as one respondent reports] "I know we don’t mean it”" ( Cass and Agiesta, 2011a, Cass and Agiesta,

2011b and Greene, 2011).

Often in close relationships or in relationships between those that are closely alike, interlocutors may assume that they will encounter minimal danger from face threats during their conversational interaction (presumably this assumption is of ten earned through trust and repeated interaction between friends or in-group members). Importantly, it is by virtue of this mutual understanding that the employment of jokes, insults, or slurs are rendered a safe way for building rapport or facilitating social intimacy between interlocutors. It should also be noted that if one interlocutor is too polite to another, the former may actually insult the latter by implying that the social distance or relative power between them is greater than the latter believes or wishes for it to be ( Brown and Levinson, 1978). If someone you would like to consider a close friend is hard-pressed on calling you Sir or Ma'am, they may be strategically doing so as a way to signal their perception of the social distance separating you two. By working in the opposite direction and instead speaking loosely or in accord with counter-culture norms, an in-group speaker's use of slurs might be understood to operate "as a positively polite stressing of in-group knowledge and commonality of attitudes” ( Brown and Levinson, 1978, p. 28).

Furthermore, since scholars have noted that "prosody of ten plays a crucial role in sense-making" (Keevallik, 2010, p. 800; see also Couper-Kuhlen and Selting, 1996, Couper-Kuhlen and Ford, 2004 and Golato and Fagyal, 2008), it is clear that speakers may strategically employ any of the phonological (as well as morphological and syntactic) features distinctive of AAVE - especially feature (5) higher rates of non-rhoticity or $r$-less-ness ( Labov et al., 1968, Williamson, 1968, Wolfram, 1969, Foley, 1972, Baugh, 1983, Pederson et al., 
1986-1992, Myhill, 1988, Edwards, 1997 and Wolfram and Thomas, 2002) - in order to express and further reinforce solidarity with each other as fellow in-group members ( Thomas, 2007, p. 451). ${ }^{10}$ Since these features are most typically displayed in the speech of, and so most characteristically associated with the speech of, the vernacular form spoken primarily by working-class Af rican Americans, a speaker wanting to indicate their similarity to some particular working-class African American interlocutor may intend to indicate this by speaking in their same vernacular form. In choosing to speak in accord with the speech patterns typical of one's interlocutor (for instance, in AAVE) a speaker can strategically signal that they belong to the same group (for instance, to signal that one is also a working-class African American as opposed to an upper-class African American). By indicating through the use of a similar speech pattern or style that the interlocutors are both members belonging to the same social group, the speaker can thereby indicate that there is little or no social distance between them. As a result of the speaker indicating that there is little or no social distance between them, the speaker can thereby indicate that it is unlikely to be the case that the speaker is using the slur derogatorily since the derogatory uses of slurs are typically used for the purpose of increasing the difference in asymmetrical power relations between the interlocutors involved or between the social groups to which they belong more generally. Thus, by choosing to sincerely speak in accord with the speech patterns typical of one's interlocutor (for instance, in AAVE) a speaker can strategically signal their distance away from the derogatory attitudes associated with an out-group (which does not speak in accord with the same speech patterns) that might presumably have a motive for derogating them (i.e., those that are similar are prima facie less likely to derogate each other than those that are not). I provide a concrete example of this idea below:

$$
\text { Nigger }+ \text { feature } 5 \text { of AAVE ( } r \text {-less-ness) }=\text { Nigga }
$$

Relatively more derogatory $\rightarrow$ Relatively less derogatory

Presumably, the more features that the interlocutors share in common, such as common speech patterns, race, sex, socio-economic class, etc., - and thus the more points in which the interlocutors can be regarded as fellow in-group members - the less likely it would be that derogation would occur between them. So speakers might employ an increasing number of similar features in order to indicate an increasing likelihood of the slur being used in a non-derogatory, in-group way. Again, this is the idea represented in the example above.

Furthermore, in cases where the speaker is clearly not a fellow group member (say they are ostensibly European American and so not possibly a working-class African American) a speaker might still choose to speak in accord with the speech patterns typical of their interlocutor to strategically signal that they are at least on familiar enough terms with the linguistic practice of their group (e.g., working-class African Americans) to attempt to enact the speech patterns of their hearer instead of simply enacting their own; insofar as such an attempt is sincere, this could be understood as a form of cultural consideration, a granting of respect for how others do things and a participatory attempt to go along. Obviously, this is also a form of risk-taking on the speaker's part, since she may not pull this off correctly and may appear foolish, incompetent, or simply prejudice because of it. But on the other hand, it could also possibly be received as a warm gesture from someone wishing to take up a conversational interaction as equals (Sweetland, 2002). "Using nigga to address and refer can contribute to the construction of a speaker's identity," Rahman (2012) suggests, but "it can also ascribe identity to a referent or addressee as a coparticipant in the diaspora" (p. 154; Coupland, 2007). In short, saying something as your interlocutor would say something seems like the least hostile way to say it, especially if that something you're about to say could be taken the wrong way. Or at least this seems to be the line of thought Charles Colton (2004) famously expressed in Lacon: Or Many Things In Few Words: "imitation is the sincerest of flattery."

Additionally, instances of non-derogatory in-group uses of slurs are not restricted to racial slurs, but extend also to slurs of other kinds such as sexist slurs. For instance, it has been pointed out that the non-derogatory in-group use of slurs is especially prevalent in communities highly influenced by "counterculture" norms (i.e., norms adopted in opposition to, and for the purpose of subverting, other entrenched sociocultural norms that 
a group contests), such as those associated with the movement SlutWalk. Because members of movements like SlutWalk position themselves in opposition to an entrenched convention or sociocultural norm, they also often find it important to distinguish their appearance and behavior with a marked unconventionality. This mark of unconventionality may also involve subverting derogation through linguistic appropriation such that between in-group speakers the slur is used as a norm reversed variant of the original derogatory use, and thus understood between in-group speakers as intended non-derogatorily. For instance, sexist slurs such as slut and bitch have also been popularly appropriated for in-group use ( Kleinman et al., 2009, Schillinger, 2010 and Angyal, 2011), with "the word "queer" [serving] as an example of a[nother] word that was once strictly pejorative but is now a common sexual identif ier used by the LGBT community" ( Stampler, 2011). This point is further illustrated below with the conversation between Tina Fey and Amy Poehler:

Tina Maybe what bothers me the most is that people say that Hillary is a bitch. Let me say something about that: Yeah, she is. So am I and so is this one. [Points to Amy Poehler].

Amy Yeah, deal with it.

Tina You know what, bitches get stuff done. That's why Catholic schools use nuns as teachers and not priests. Those nuns are mean old clams and they sleep on cots and they're allowed to hit you. And at the end of the school year you hated those bitches but you knew the capital of Vermont. So, I'm saying it's not too late Texas and Ohio, bitch is the new black! (quoted in Kleinman et al., 2009, p. 63).

It has also been pointed out that in Meredith Brooks' (1997) hit song "Bitch," Brooks did not use the term in a derogatory sense but rather to express the "sexy side of the woman" (Kleinman et al., 2009, p. 62). Further, it has been reported that "Women who address women as "bitches" [...] with friendly intentions, find the term cool" and that nowadays "women would rather call themselves or other women bitches - rather than feminists" (Kleinman et al., 2009, p. 60,65). The representatives of SlutWalk, an influential movement including thousands of individuals, expressed their perspective concerning slurs over a radio broadcast in the following way:

\begin{abstract}
One of the most effective ways to fight hate is to disarm the derogatory terms employed by haters, embracing them and giving them positive connotations. This also serves to provide a sex-positive term for women (and men), few or none of which currently exist, and allows sluts (individuals of any gender who have and enjoy frequent consensual sex, especially with multiple partners) to identify as part of a cohesive group for political representation. We feel that offering a place for women who lead such a lifestyle to self-identify as sluts does not disrespect them - indeed, the disrespecting is done by the rapists, the victim blamers who excuse the rape, and the slut shamers who say or imply they are disgracing, degrading, and dishonoring themselves. ${ }^{11}$ (Murray et al., 2011)
\end{abstract}

Presumably the explanation for why members of this in-group (based on a type of sex-based characteristic) can exchange slurs with one another in a way that is intended and understood as non-derogatory or nonoffensive is similar to the explanation for why members of other in-groups (e.g., based on a type of racebased characteristic) can exchange slurs with one another in a way that is intended and understood as nonderogatory or non-offensive. That is to say, in such in-group uses the sex-based slur can be used as a form of "mock impoliteness" since it is understood as intentionally non-offensive (Culpeper, 1996). This is presumably made possible by the fact that these in-group members share in many of the same sex-based problems and face many of the same sex-based prejudices, so in-group uses of such slurs can serve as a way for like-speakers to signal to each other that they are not alone and that others like them share in their experiences, perspectives, and history of sex-based prejudices. This might serve as a means for like speakers to foster a sense of solidarity, namely, by being in on this in-group use of the sex-based slur. 
As it has been noted in the case of racial slurs (Rahman, 2012, p. 155), sexist slurs might also be used "to show solidarity stemming from a particular bond with a reliable friend," and although this non-derogatory ingroup use of the slur is diametrically opposed to the original derogatory use of the slur, "ordinary language is [...] in a constant state of evolution" (Parker-Ryan, 2012, Section 1). Indeed, Jucker and Taavitsainen (2003) argue that the choices that speakers make concerning the address forms that they use are always "culturally dependent and change in the course of time as old criteria become obsolete and come to be replaced by new criteria" (p. 4; see also Nevala, 2004 and Fitzmaurice, 2010).

To briefly review, in the last three sections my aim has been been to track and make sense of three different kinds of uses for slurs: (a) the paradigmatic derogatory use of slurs, (b) the non-paradigmatic derogatory use of slurs, and (c) the non-derogatory in-group use of slurs. Next, we will consider in further detail what a literal meaning for slurs might plausibly look like.

\section{A literal meaning for slurs}

We have now reviewed how slurs are of ten put to use in different ways and have discussed three such uses: (a) paradigmatic derogatory uses of slurs, (b) non-paradigmatic derogatory uses of slurs, and (c) nonderogatory in-group uses of slurs. But how do speakers understand the meaning of slurs and how to use slurs in such diverse ways? Now, it is typically assumed in the literature that "every word is associated with a conventional meaning which is either a property or relation" ( Parikh and Clark, 2007, p. 97), yet even among semantic theorists little work has been done to explicate the conventional or literal meaning of particular slurs ( Anderson and Lepore, 2013, p. 27). Intuitively, theorists that claim that slurs have literal meaning are tasked with explicating what it is. Typically, previous theorists have suggested that a slur such as kraut really means something like German and bad because of it (McCready, 2010) and that a slur such as nigger really means something like African American and despicable because of it ( Saka, 2007) or African American and a fit object for derision because of it (Blackburn, 1984). As I will now point out, these suggestions are inadequate as analyses of the literal meaning of slurs. In this section, I will propose a more apt analysis of the literal meaning of the racial slur nigger. I will compare my analysis with the other competing proposals, and demonstrate in which ways my account is more reasonable. If it is correct, it may serve as a model for understanding other slurs of various kinds - like chink and slut - that target members associated with different classes.

My view is that slurs have mixed content, in the sense that the use conditions of racial slurs (such as nigger) typically have both expressive and descriptive aspects. As a racial slur, by choosing to use the slur nigger instead of a neutrally descriptive term such as African American, the speaker prima facie intends to express (i) their endorsement of a (typically but not necessarily negative) attitude (ii) towards the descriptive properties possessed by the target of their utterance. For instance, consider the following felicitous utterance documented in Alex Haley's (1964)The Autobiography of Malcom X:

Now we all here like you, you know that. But you've got to be realistic about being a nigger. A lawyer - that's no realistic goal for a nigger. You need to think about something you can be. (p. 38)

This example is illuminating, for it suggests that (i) holds because the phrase "But you've got to be realistic about being a nigger" communicates the speaker's endorsement of a negative attitude. It also suggests that (ii) holds because the phrase "Now we all here like you, you know that" suggests that what the negative attitude being expressed by the speaker is directed towards is not the agent, but rather some set of the agent's properties. That is to say, the properties that the speaker endorses the expression of a negative attitude towards are properties that have been associated with members of a particular racial group, and as a result, the speaker does not directly express a negative attitude towards the agent him or herself. Indeed, in this example the speaker explicitly says that they like the target. However, an agent might indirectly express a 
negative attitude towards a target by expressing a negative attitude towards some set of properties that that target possesses.

Slurs usually derogate, ridicule, or demean members of a certain class by targeting certain properties or features associated with those members as a class. For instance, African Americans that have been derogated with the slur nigger have typically been derogated on the basis of being "emotionally shallow, simple-minded, sexually licentious, and prone to laziness" ( Asim, 2007, p. 27). It is in such contexts where a speaker intends to ascribe at least some such properties to a target that the slur nigger has typically been employed. Importantly, notice that since the properties that the speaker is endorsing the expression of a negative attitude towards are properties that have been typically associated with members of a particular racial group (for instance African Americans), it is possible for these same negative properties to be ascribed to members of a different racial group. In other words, it is surely possible that some of the properties that have been typically associated with African Americans can be properties that are also ascribed to someone that is not Af rican American. For example, if stamina had been typically associated with African Americans, this does not by any means restrict us from applying the term stamina to, say, Chinese Americans. Therefore, my analysis of the slur nigger avoids the problems that others inevitably face. That is, since McCready, 2010, Williamson, 2009, Saka, 2007 and Blackburn, 1984, and others assume that nigger literally means the same as African American and that faggot literally means the same as homosexual, they are unable to account for cases where the slur nigger is in fact felicitously ascribed to non-African American individuals (MacDonald, 2000) and for cases where the slur faggot is in fact felicitously ascribed to non-homosexual individuals (Szekely, 2008). My account does not share this widely held assumption, for I have argued that the negative attitude typically expressed by the speaker using e.g. the slur nigger need not necessarily be directed towards an agent that is African American, but rather can be directed towards some set of properties associated with African Americans that the target agent (who may be African American or not) is thought to possess.

My point is made clear below, where (16a) provides an example context, (16b) provides an example sentence, and (16c) and (16d) provide competing paraphrases. (16c) provides a standard paraphrase common of the aforementioned scholars, whereas $(16 \mathrm{~d})$ provides an example of my own original paraphrase. In the original context, a comedian asks the crowd:

(16a) "Is you a nigger?" All of them answer in the affirmative, including blacks, whites, Latinos, and a Sicilian, who proclaims, "I'm more of a nigger than any nigger in here." (quoted in Asim, 2007, p. 193)

(16b) I'm more of a nigger than any nigger in here.

(16c) [l'm more of a [nigger] than any [nigger] in here] = l'm more of a [person that is Af rican American and despicable because of it] than any [person that is African American and despicable because of it] in here.*

(16d) [l'm more of a [nigger] than any [nigger] in here] = l'm more of a [person with a set of negatively viewed properties that have been associated with Af rican Americans] than any [person with a set of negatively viewed properties that have been associated with Af rican Americans] in here.

In this case, (16c) is clearly bizarre, because it seems infelicitous for people that are not Af rican American to assert that they are African American and despicable because of it. On the other hand, although (16d) is somewhat cumbersome, it is perfectly adequate. For instance, even though it seems inf elicitous for people that are not African American to assert that they are African American and despicable because of it, it is not inf elicitous for people that are not African American to assert that they are people that possess a set of negatively viewed properties that have been associated with African Americans. In other words, because the speaker intends to communicate an attitude towards some set of properties associated with Af rican Americans, his attitude need not be restricted to actual African Americans at all. People of other races may also share these same negatively viewed properties. However, unless otherwise indicated, it is generally assumed that 
those who possess the properties typically associated with African Americans are most likely to be actual Af rican Americans. But notice that this still leaves open the possibility that, although speakers usually ascribe the term nigger to Af rican Americans, it is still felicitous under certain circumstances to ascribe the term nigger to non-African Americans insofar as these non-African Americans are assumed to possess the negative properties typically associated with African Americans. Therefore, unlike the proposals offered by other scholars, my analysis is the first that can account for cases where the racial slur nigger is in fact felicitously ascribed to non-African American individuals (MacDonald, 2000) and for cases where the sexist slur faggot is in fact felicitously ascribed to non-homosexual individuals ( Szekely, 2008). As these cases represent actual and widespread uses of slurs, accounting for them is a virtue of my analysis that is absent in others.

Furthermore, my analysis captures our intuitions about the literal meaning of the racial slur in different kinds of conversational contexts while still remaining sufficiently general so as to be systematically applicable to other cases.

\section{Criterial features, category membership, and family resemblance concepts}

While everyday speakers, such as Louis C.K. and Michael MacDonald, find it quite natural that the felicitous use of slurs need not be restricted by any one criterial feature such as the target's racial identity (see Section 8 , Slurs II: The non-paradigmatic derogatory use of slurs), some traditional philosophers and linguists may find this result intuitively unappealing. As these traditionalists or classicalists might argue, since the slur nigger has most often been ascribed to African Americans and has been used to derogate them, the felicitous application of that term presumably must be restricted to African Americans. The purpose of this final section is to suggest that this traditional assumption is too strong. Indeed, empirical work by Rahman (2012) suggests that there are often various social meanings associated with a racial slur, and that a "reason for the continued use of nigga is its genuine versatility as a linguistic resource" (p. 163). Other scholars have likewise argued for the potential of extending and even transforming the meanings traditionally associated with slurs to create new meanings ( Allen, 1983, Bauman and Briggs, 1990, Ochs, 1992, Butler, 1997, Coupland, 2007 and Kecskes, 2008). In order to capture this fact regarding the "versatility" of slurs, I propose that my analysis of slurs can be combined with a family-resemblance conception of category membership, and that this offers an explanatorily powerful and true to the facts account of the various empirical uses of slurs (although my account of slurs does not require all concepts to be restricted to a family-resemblance account).

As individuals participate in social and cultural contexts with others, they employ cognitive resources representing the schematic organization of those social and cultural contexts (Jackendoff, 1992). In the psychological literature, human concepts have of ten been categorized as falling into one of two groups: as either classical categories or family resemblance categories. The traditional or classical view, which was widely held in the linguistic and philosophical literature, was that category membership is determined by the possession of some common, essential, criterial feature or property (Rosch and Mervis, 1975). As Pinker and Prince (1996) explain, "Classical categories are defined by formal rules and allow us to make inf erences within idealized law-governed systems" (p. 332). Although these "classical categories" are def ined by necessary and sufficient criteria that determine whether an object is a category member or not, linguists and philosophers of language have in general been unable to adequately articulate necessary and sufficient conditions for most concepts of natural language (Fodor et al., 1980 and Pinker and Prince, 1996). It has also been argued that human memory has an easier time processing family resemblance categories than classical categories (Pinker and Prince, 1996; see also Rosch and Mervis, 1975), and empirical research on children has suggested that they first learn to classify items as members of the same category, not on the basis of those members possessing some common criterial feature (Vygotsky, 1962, Bruner et al., 1966 and Rosch and Mervis, 1975), but rather by means of the formation of "complex structures" and groupings that are more in line with the family resemblance conception of category membership (Rosch and Mervis, 1975 and Bruner et al., 1966).

Accordingly, a popular contemporary view is that most concepts of natural language correspond, not to classical categories, but instead to prototype or family resemblance categories. Rosch and Mervis (1975), 
drawing on the philosophical work of Wittgenstein (1953), call this form of categorical membership a "family resemblance relationship," which is a relationship of items in a category where "each item has at least one, and probably several, elements in common with one or more other items, but no, or few, elements are common to all items" (p. 575; for other work suggesting that human concepts correspond to family resemblance categories see also Rosch, 1973, Rosch, 1978, Smith and Medin, 1981, Bybee and Moder, 1983, Smith et al., 1984, Lakoff, 1987, Rosch, 1988 and Pinker and Prince, 1996). "Family resemblance categories," according to Pinker and Prince (1996), "are generalizations of patterns of property correlations within a set of memorized exemplars" (p. 325) and differ from classical categories in a number of ways, including (1) family resemblance categories lack necessary and sufficient conditions for membership, (2) family resemblance categories have graded degrees of membership, (3) a family resemblance category can be summarized by an ideal member or prototype, which is sometimes but not always an actual exemplar of the category, (4) there are sometimes unclear cases for family resemblance categories - that is, cases where it is unclear whether an object belongs or does not belong to the category under consideration, (5) family resemblance categories of ten display a family resemblance structure, and (6) good members of family resemblance categories tend to have characteristic nondefining features (Pinker and Prince, 1996, p. 308).

As Rosch and Mervis (1975) explain:

The more prototypical a category member, the more attributes it has in common with other members of the category and the less attributes it has in common with contrasting categories. Thus, prototypes appear to be just those members of the category which most reflect the redundancy structure of the category as a whole. That is, categories form to maximize the information-rich clusters of attributes in the environment. (p. 602)

For instance, regarding the concept art, Weitz (1956) has argued that the "attempt to discover the necessary and sufficient properties of art is logically misbegotten," and that the "contention that "art" is amenable to real or any kind of true definition is false" because art "has no set of necessary and sufficient properties" (p.28; for discussion see also Kaufman, 2007, Tilghman, 2008 and Irwin, 2011). So on this view, there is no feature $x$ such that the possession of $x$ is necessary and sufficient for some object $y$ to be categorized as an artistic one. Instead, this view suggests that for each of the various objects that we categorize as art, we will more realistically find "a complicated network of similarities [among them that are] overlapping and criss-crossing: sometimes overall similarities, sometimes similarities of detail" ( Wittgenstein, 1953, Section 66). The family resemblance conception of category membership, therefore, seems most appropriate for the analysis of slurring terms, especially since it has been argued that, "derogation begins with shared stereotypes that allow negative social meanings to attach to a previously neutral term" (p. 7) and that "the meanings of the terms sometimes overlap, compete, and even support one another; their interaction is highly complex" ( Anderson, 1999, p. 143).

So on the family-resemblance conception of category membership, what makes some individual a member of the category DOG is not some criterial feature or property that all and every individual must have in order to be considered a dog. As Pinker and Prince (1996) suggest, "Family resemblance categories are defined by correlations among features in sets of similar memorized exemplars, and allow us to make inferences about the observable products of history" (p. 353). So in line with the family-resemblance conception, I suggest that we view some categories of natural language as constellations of properties or features. In applying such categories in order to communicate some content to a hearer, speakers are able to choose among the categories available in their lexical inventory to pick out that which is, although not necessarily an "ideal" choice (note that one might even question what "ideal" would mean in such cases, given the tradeoffs required to maximize on precision, economy of expression, or politeness strategies), at least their most apt choice for their current conversational purpose. For instance, a paradigmatic or prototypical dog may have a tail and bark, 
but surely a speaker can still felicitously and informatively refer to an individual as a dog even if that individual does not have a tail and does not bark, provided that the category DOG is that which is strategically most apt among the lexical choices available for the speaker's conversational purpose.

For instance, assume that the family resemblance category (C) Dog consists in a network of properties (P) such as those displayed below:

\begin{tabular}{ll} 
C. & $D(D o g)$ \\
\hline P1. & $X$ has four legs \\
\hline P2. & $X$ has a tail \\
\hline P3. & $X$ barks \\
\hline P4. & $X$ has a keen sense of smell \\
\hline P5. & $X$ urinates on trees \\
\hline P6. & $X$ has shaggy hair \\
\hline P7. & $X$ chases cats and objects that roll \\
\hline P8. $\quad X$ likes to play catch \\
\hline P9. $\quad X$ is loyal \\
\hline
\end{tabular}

P10. $X$ is a pack animal

These properties (P1)-(P10) could be ranked in the order to which their possession by an individual $X$ is taken as a salient indicator of category membership (with the relative rankings of these properties being adjustable or "updatable" in accord with changes in context). For instance, properties (P1), (P2), and (P3) would be ranked relatively higher than properties (P6), (P7), and (P8), and so the former set of properties would be considered more salient indicators than the latter set of properties that the individual possessing them is a member of the category DOG. In other words, a prototypical dog would possess the highest ranking and highest number of properties in (P1)-(P10), although an individual can still informatively be considered as a dog while failing to possess some of the properties in $(\mathrm{P} 1)-(\mathrm{P} 10)$ or even the highest ranking property $(\mathrm{P} 1)$. However, for the speaker's choice to refer to a target individual as a dog to be considered a strategically apt choice, it must be thought (or at least assumed for the purpose of the conversation) that the target individual possesses a sufficient set of properties (P1)-(P10) such that DOG is the most appropriate or serviceable category under which to subsume the individual for the purposes of the speaker's current conversational aim. That is, the category DOG must be a strategically better choice than other categories available in the speaker's lexicon for the conversational purpose at hand. So in contrast with the traditional view where the possession of some criterial feature or property was thought to be essential for an individual's being a member of some category, Rosch and Mervis suggest that e.g. although different dogs will share different sets of (P1)-(P10) with other dogs, it need not be the case that for each dog, it must share some essential criterial feature or property with every other dog. On a family-resemblance account of category membership, an individual may even fail to possess the highest ranking or most salient indicator of category membership while still being best considered a member of that category for the current conversational purpose at hand.

I suggest that Rosch and Mervin's family-resemblance analysis may be fruitfully extended to explain how speakers actually employ slurs in real life cases. For instance, assume that the family resemblance category (C) designated by the term bitch - call this category $B$ - consists in a constellation of properties $(P)$ such as those displayed below: 
C. $B($ Bitch $)$

P1. $\quad X$ is female (Kleinman et al., 2009, p. 61)

P2. $\quad X$ is weak or unaggressive ( Sabo, 2001 and Messner, 2002)

P3. $\quad X$ is dependent on others or the subordinate partner in a (often sexual) relationship ( Jay- $Z$, 2002 and Heffernan, 2005, para. 3; Kleinman et al., 2009, p. 52)

P4. $X$ is commonly the recipient of poor treatment ( Jay-Z, 2002 and Kleinman et al., 2009, p. 50, 59)

P5. $\quad X$ is sexually liberal or promiscuous ( Jay- Z, 2002)

P6. $\quad X$ is provocative or sexually appealing (Brooks, 1997 and Kleinman et al., 2009, p. 62)

P7. $X$ is manipulative, nosy, catty, inconsiderate, or insensitive of others ( Jay- Z, 2002 and Kleinman et al., 2009, p. 59, 61)

P8. $\quad X$ is a liar, complainer, or talks about others in a disparaging way behind their back ( Jay- $Z$, 2002 and Kleinman et al., 2009, p. 54, 61)

P9. $\quad X$ is materialistic, success-oriented, or focused on the bottom line ( Clark-Flory, 2008 and Kleinman et al., 2009, p. 56)

P10. $X$ is one to start trouble with other community or in-group members ( Jay-Z, 2002)

These properties (P1)-(P10) could be ranked in the order to which their possession by an individual $X$ is taken as a salient indicator of category membership (with the relative rankings of these properties being adjustable or "updatable" in accord with changes in context). For instance, property ( $\mathrm{P} 1)$ would be ranked relatively higher than property (P6), and so (P1) would be considered a more salient indicator than (P6) that the individual possessing it is a member of the category $B$. In other words, although (sexist or in-group) speakers may typically ascribe the term bitch to females, (sexist or in-group) speakers may still informatively or effectively ascribe that slur to someone that fails to be female for their conversational purpose. However, for the (sexist or in-group) speaker's choice to refer to a target individual as a bitch to be considered a strategically apt choice, it must be thought (or at least assumed for the purpose of the conversation) that the target individual possesses a sufficient set of properties in (P1)-(P10) such that $B$ is the most appropriate or serviceable category under which to subsume the individual for the purposes of the speaker's current conversational aim (which may be to derogate or build rapport with some hearer). For instance, if a speaker is intending to communicate that some target that they dislike possesses some subset of properties (P2)-(P10) - such as in the case Sabo (2001) describes regarding the "male bitches" that ended up in prison (p. 9; see also Heffernan, 2005, para. 3; Kleinman et al., 2009, p. 52) - that speaker might strategically choose to employ $B$ as the category that most efficiently and economically predicates the intended properties of their target and most forcef ully expresses a negative attitude towards them, at least to the extent that $B$ is better for this than other categories available to the speaker in their lexical inventory.

Additionally, if for instance an in-group speaker is intending to communicate that they are sufficiently similar to some hearer insofar as they both possess properties (P1), (P4), and possibly others (such as (P5) and (P6), or (P9)), and if these interlocutors know each other well-enough or have established enough common ground to understand that the speaker does not dislike the target and does not intend to communicate that the target possesses most of the other (typically negative) properties belonging to $B$, an in-group speaker might strategically choose to employ $B$ as the category that most efficiently and economically predicates the intended (shared) properties of their target such as e.g. (P1) female, (P4) commonly the recipient of poor treatment, and possibly others (such as (P5) sexually liberal and (P6) sexually appealing, or (P9) successoriented), at least to the extent that $B$ is better for this than other categories available in the speaker's lexicon. 
So in contrast with traditional views of slurs, where the possession of some criterial feature or property (being female) was assumed to be essential for an individual's being a member of some category (the category $B$ ), I suggest that e.g. although different individuals that are referred to as bitches are likely to share different subsets of properties (P1)-(P10) with other individuals also referred to by this pejorative term, it need not be the case that for each slurred individual they must share some criterial feature or property (such as being female) with every other slurred individual. In line with the family-resemblance account of category membership, I suggest that an individual referred to by the slur bitch may even fail to be female, while the employment of that slur on part of the speaker may still be considered by that speaker to be strategically apt enough for their current conversational purpose.

As with the sexist slur bitch, let us similarly assume that the family resemblance category (C) designated by the term nigger - call this category $N$ - consists in a constellation of properties $(P)$, such as those displayed below:

C: $\quad N($ Nigger $)$

P1. $\quad X$ is African American ( Fredrickson, 1971, Asim, 2007 and Williamson, 2009)

P2. $\quad X$ is prone to laziness (Asim, 2007, p. 27)

P3. $\quad X$ is subservient ( Fredrickson, 1971 and Asim, 2007)

P4. $\quad X$ is commonly the recipient of poor treatment (Fredrickson, 1971 and Asim, 2007)

P5. $\quad X$ is athletic and musical ( Alim et al., 2010, p. 128)

P6. $\quad X$ is sexually liberal or licentious ( Asim, 2007, p. 27)

P7. $\quad X$ is simple-minded (Asim, 2007, p. 27)

P8. $\quad X$ is emotionally shallow ( Asim, 2007, p. 27)

P9. $\quad X$ is a survivor, tough, or prone to violence ( Anderson, 1999, p. 50; Rahman, 2012)

P10. $X$ is loud and excessively noisy (Anderson, 1999, p. 50)

These properties (P1)-(P10) could be ranked in the order to which their possession by an individual $X$ is taken as a salient indicator of category membership. For instance, property (P1) would be ranked relatively higher than property (P6), and so (P1) would be considered a more salient indicator than (P6) that the individual possessing it is a member of the category $N$. In other words, although (racist or in-group) speakers may typically ascribe the term nigger to African Americans, (racist or in-group) speakers may still informatively or effectively ascribe that slur to someone that fails to be African American for their conversational purpose. However, for the (racist or in-group) speaker's choice to refer to a target individual as a nigger to be considered a strategically apt choice, it must be thought (or at least assumed for the purpose of the conversation) that the target individual possesses a sufficient set of properties in (P1)-(P10) such that $N$ is the most appropriate or serviceable category under which to subsume the individual for the purposes of the speaker's current conversational aim (which may be to derogate or build rapport with some hearer). For instance, if a speaker is intending to communicate that some target that they dislike possesses some subset of properties (P2)-(P10) - such as in the case MacDonald (2000) describes regarding the "white niggers" that ended up on D Street (pp. 60-61) - that speaker might strategically choose to employ $N$ as the category that most efficiently and economically predicates the intended properties of their target and most forcefully expresses a negative attitude towards them, at least to the extent that $N$ is better for this than other categories available to the speaker in their lexical inventory. As we would all agree, if one wished to express their contempt for a target by linguistic means, hardly any words could serve this purpose better than slurs such as nigger. 
Additionally, if for instance an in-group speaker is intending to communicate that they are sufficiently similar to some hearer insofar as they both possess properties (P1), (P4), and possibly others (such as (P5) and (P6), or (P9)), and if these interlocutors know each other well-enough or have established enough common ground to understand that the speaker does not dislike the target and does not intend to communicate that the target possesses most of the other (typically negative) properties belonging to $N$, an in-group speaker might strategically choose to employ $N$ as the category that most efficiently and economically predicates the intended (shared) properties of their target such as e.g. (P1) African American, (P4) commonly the recipient of poor treatment, and possibly others (such as (P5) athletic and musical, (P6) sexually liberal, or (P9) a survivor), at least to the extent that $N$ is better for this than other categories available in the speaker's lexicon.

So in contrast with traditional views of slurs, where the possession of some criterial feature or property (being African American) was assumed to be essential for an individual's being a member of some category (the category $N$ ), I suggest that e.g. although different individuals that are referred to as niggers are likely to share different subsets of properties (P1)-(P10) with other individuals also referred to by this pejorative term, it need not be the case that for each slurred individual they must share some criterial feature or property (such as being African American) with every other slurred individual. In line with the family-resemblance account of category membership, I suggest that an individual referred to by the slur nigger may even fail to be Af rican American, while the employment of that slur on part of the speaker may still be considered by that speaker to be a strategically apt enough choice for their current conversational purpose.

In order to capture the "versatility" of slurs, I proposed in this section that my analysis of slurs could be combined with a family-resemblance conception of category membership, and that this offers an explanatorily powerful and true to the facts account of the various empirical uses of slurs. I have now provided an original and detailed outline for how this might be represented above. It is important to note that although speakers can often use slurs in various and somewhat flexible ways, there seems to be strategies and constraints involved in guiding both the use and interpretation of slurs. In addition to those already discussed throughout the course of the present work, it is important to note that speakers typically pick derogatory terms to derogate, but typically the conditions under which derogation occurs are conditions where the properties of the speaker and target are sufficiently different (e.g., as members of different out-groups they presumably differ at least in skin color or sex, etc.). In contrast, typically the conditions under which in-group uses of the term occur are conditions where the properties of the speaker and target are sufficiently similar (e.g., members of the same in-group share in similar features such as skin color or sex, etc.). So it is less likely than otherwise that derogation would occur in conditions where the properties of the speaker and target are sufficiently similar, and less likely than otherwise that in-group signification would occur in conditions where the properties of the speaker and target are sufficiently different. Knowledge of this, as well as knowledge of the other factors previously discussed throughout this work, is part of that very valuable street knowledge of how to slur, who to slur, and when not to.

\section{Conclusion}

In conclusion, the present article was organized as follows. Section 1 provided an introduction and Section 2 briefly discussed what slurs are. Section 3 focused on distinguishing between descriptive, expressive, and slurring terms, and in this section I argued that slurs are best characterized as being of a mixed descriptive/expressive type. Section 4 focused on discussing language and its important role in social interaction. Section 5 then discussed language and social identity, pointed out over 20 features of African American Vernacular English (AAVE), and explained how these features have been argued to form a speech pattern that is distinctive to working-class African Americans and reliably indicates a unique sense of racial identity among its speakers. Section 6 focused on discussing social stratification and the basis for out-group derogation, and Section 7 turned to discuss the paradigmatic derogatory use of slurs. After discussing another use of slurs in Section 8, the non-paradigmatic derogatory use, Section 9 focused on discussing how 
derogation is subverted through appropriation and how slurs can and of ten are frequently appropriated by the very in-group members that the slur was originally intended to target. Section 10 focused on providing a new analysis of the literal meaning of slurs and explained in which ways it is superior to others. Section $11 \mathrm{focused}$ on discussing criterial features, category membership, and family resemblance concepts, and in this section I suggested that a family-resemblance conception of category membership can help us achieve a clearer understanding of the various ways in which slurs are actually put to use in natural language discourse. Finally, in closing, I would like to suggest the following as a minimal set of desiderata to be met by any future, explanatorily successful account of slurs.

Slurs are not purely descriptive terms, and so an analysis of slurs must account for the fact that slurs are also expressive of attitudes or emotions.

Slurs are not purely expressive terms, and so an analysis of slurs must account for the fact that slurs also target descriptive features.

Slurs have non-derogatory correlates - or at least there are alternative lexical options available to speakers such that their use of the slur over a neutral counterpart typically expresses a strategic choice that can signal derogatory intent towards a target - and so the speaker's choice to use the slur is often taken to indicate their approval of the slurring term and what it is typically used to convey.

Slurs, at least prima facie, typically carry derogatory content and force across different conversational contexts. This typical use was called the paradigmatic derogatory use of slurs.

Slurs can be felicitously applied towards individuals that do not belong to the group typically associated with the slur; for instance, the racial slur nigger is felicitously used by some speakers towards individuals that are not African American and the sexist slur faggot is felicitously used by some speakers towards individuals that are not homosexual. This was called the non-paradigmatic derogatory use of slurs.

Slurs can also be used non-derogatorily, for instance in an appropriative manner between in-group speakers. This was called the non-derogatory in-group use of slurs.

Several markers that aid in the interpretation of slurs as being used non-derogatorily rather than derogatorily include sameness of target features (e.g., members of the same racial in-group using the relevant racial slur between each other, members of the same sexual in-group using the relevant sexist slur between each other, etc.) as well as sameness of communicative medium and style (e.g., members both communicate in the same language and speech style, such as AAVE, etc.). There are likely to be other markers also, but sameness of target features and sameness of communicative medium and style seemed most important to discuss for the purposes of the present work, so I have modestly limited the discussion here to those. 


\section{Acknowledgments}

I would like to give special thanks to my two wonderful advisors, Liz Camp and Robin Clark, for their influence, encouragement, and constructive criticism. I would also like to give sincere thanks to Luvell Anderson, Rosalie Genova, Sally Haslanger, Nigel Love, Susan Schneider, and Rogers Smith, who have all given me useful feedback at some point during my research on slurs. Sections of this article were presented at several conferences, including the Fourth North American Summer School in Logic, Language, and Information at Indiana University in 2010, as well as the Program on Democracy, Citizenship, and Constitutionalism Annual Conference at the University of Pennsylvania in 2012, and I thank the fellow participants at those events for their feedback and support. Finally, I thank the Andrew W. Mellon Foundation and the Program on Democracy, Citizenship, and Constitutionalism at the University of Pennsylvania for generously offering me financial support to carry out part of this research.

\section{References}

1.

- Alim, 2006

○ H. Alim

- Roc the Mic Right: The Language of Hip Hop Culture

- Routledge, New York (2006)

2.

- Alim et al., 2010

- H. Alim, J. Lee, L. Carris

- "Short fried-rice-eating Chinese MCs" and "good hair-havin uncle Tom niggas": performing race and ethnicity in freestyle rap battles

- Journal of Linguistic Anthropology, 20 (2010), pp. 116-133

- View Record in Scopus

I

Full Text via CrossRef

I

Cited By in Scopus (7)

3.

- Allan and Burridge, 2006

- K. Allan, K. Burridge

- Forbidden Words: Taboo and the Censoring of Language

- Cambridge University Press, New York (2006) 
4.

- Allen, 1983

- I. Allen

- The Language of Ethnic Conflict: Social Organization and Lexical Culture

- Columbia University Press, New York (1983)

5.

- Anderson, 1999

- E. Anderson

- Code of the Street: Decency, Violence, and the Moral Lif e of the Inner City

- W.W. Norton \& Co., New York (1999)

6.

- Anderson, 2008

- K. Anderson

- Justifying race talk: indexicality and the social construction of race and linguistic value

- Journal of Applied Linguistics, 2 (2008), pp. 129-151

7.

- Angyal, 2011

- Angyal, C., 2011. A Few Words About Reclaiming "Slut". Feministing, 16 May. <http://f eministing.com/2011/05/16/a-few-words-about-reclaiming-"slut"/>.

8.

- Asim, 2007

- J.Asim

- The N Word

- Houghton Mifflin Company, New York (2007)

9.

- Austin, 1962

- J.Austin

- How To Do Things with Words

- Harvard University Press, Cambridge (1962) 
10.

- Ayer, 1952

- A. Ayer

- Language, Truth and Logic

- Dover Publications, New York (1952)

11.

- Bakhtin, 1981

- Bakhtin, M., 1981. The Dialogic Imagination, University of Texas Press; Austin.

12.

- Baugh, 1983

- J. Baugh

- Black Street Speech

- University of Texas Press, Austin (1983)

13.

- BBC News, 2011

- BBC News, 2011. Eight US Troops Charged Over Death of Pte Danny Chen. BBC News, 21 December. <http://www.bbc.co.uk/news/world-us-canada-16290224>.

14.

- Beschloss and Sidey, 2009

- M. Beschloss, H. Sidey

- The Presidents of the United States of America

- White House Historical Association, Washington (2009)

15.

- Blackburn, 1984

- S. Blackburn

- Spreading the Word

- Oxford University Press, Oxford (1984) 
1.

- Blassingame, 1979

- J. Blassingame

- The Slave Community: Plantation Life in the Antebellum South

- Oxford University Press, New York (1979)

2.

- Bonnell, 1998

- V. Bonnell

- Iconography of Power: Soviet Political Posters under Lenin and Stalin

- University of California Press, Berkeley (1998)

3.

- Boyd, 2002

- T. Boyd

- The New H.N.I.C. (Head Niggas in Charge): The Death of Civil Rights and the Reign of Hip Hop

- New York University Press, New York (2002)

4.

- Brison, 2011

- Brison S., 2011. An Open Letter from Black Women to SlutWalk Organizers. The Huffington Post, 27 September. <http://www.huffingtonpost.com/susan-brison/slutwalk-blackwomen_b_980215.html>.

5.

- Brontsema, 2004

- R. Brontsema

- A queer revolution: reconceptualizing the debate over linguistic reclamation

- Colorado Research in Linguistics, 17 (2004), pp. 1-17

6.

- Brooks, 1997

- M. Brooks

- Bitch. Blurring the Edges

- Capitol (1997) 
7.

- Brown and Levinson, 1978

- P. Brown, S. Levinson

- Universals in language usage: politeness phenomena

- E. Goody (Ed.), Questions and Politeness: Strategies in Social Interaction, Cambridge University Press, New York (1978), pp. 56-289

8.

- Brown and Levinson, 1987

- P. Brown, S. Levinson

- Politeness: Some Universals in Language Usage

- Cambridge University Press, Cambridge (1987)

9.

- Browne, 2007

- Browne, K., 2007. Should Racist Word be Rehabilitated? BBC News, 1 March. <http://news.bbc.co.uk/2/hi/americas/6407413.stm>.

10.

- Bruner et al., 1966

- J. Bruner, R. Olver, P. Greenf ield

- Studies in Cognitive Growth

- John Wiley \& Sons, New York (1966)

11.

- Butler, 1997

- J. Butler

- Excitable Speech: A Politics of the Performative

- Routledge, New York (1997)

12.

- Butters and Nix, 1986

- R. Butters, R. Nix

- The English of blacks in Wilmington, North Carolina: language variety in the South

- M. Montgomery, G. Bailey (Eds.), Perspectives in Black and White, University of Alabama Press, Tuscaloosa (1986), pp. 254-263 
13.

- Cameron, 2012a

- Cameron, J., 2012a. The N-Word: Neutralising the Power to Harm with Racial Epithets. Decoded Science, 13 February. <http://www.decodedscience.com/the-n-word-neutralising-the-power-toharm-with-racial-epithets/9860.

14.

- Cameron, 2012b

- Cameron J., 2012b. Dehumanizing Others Through Racial Slurs: Interview with Adam Croom. Decoded Science, 15 February. <http://www.decodedscience.com/dehumanizing-others-throughracial-slurs-interview-with-adam-croom/10588>.

15.

- Cass and Agiesta, 2011a

- Cass, C., Agiesta, J., 2011a. Poll: Young People See Online Slurs as Just Joking. MSNBC, 20 September. <http://www.msnbc.msn.com/id/44591677/ns/technology_and_sciencetech_and_gadgets/t/poll-young-people-see-online-slurs-just-joking/>.

16.

- Cass and Agiesta, 2011b

- Cass, C., Agiesta, J., 2011b. Young People see Online Slurs as Just Joking, Poll Shows. Huffington Post, 20 September. http://www.huffingtonpost.com/2011/09/20/young-people-see-onlines_n_971803.html.

17.

- Chandler, 1999

- D. Chandler

- Voices from S-21: Terror and History in Pol Pot's Secret Prison

- University of California Press, Berkeley (1999)

18.

- Clark, 2011

- R. Clark

- Meaningful Games: Exploring Language with Game Theory

- MIT Press, Cambridge (2011)

19.

- Clark-Flory, 2008

- Clark-Flory, T., 2008. Tina Fey: Bitch is the New Black. Salon, 25 February. <http://www.salon.com/2008/02/25/f ey/>. 
1.

- Cole et al., 2008

- J. Cole, E. Thomas, E. Britt, E. Coggshall

- Gender and Ethnicity in Intonation: A Case Study of North Carolina English

- Ms. University of Illino is at Urbana-Champaign and North Carolina State University (2008)

2.

- Couper-Kuhlen and Ford, 2004

- E. Couper-Kuhlen, C. Ford

- Sound Patterns in Interaction: Cross-Linguistic Studies from Conversation

- John Benjamins, Philadelphia (2004)

3.

- Couper-Kuhlen and Selting, 1996

- E. Couper-Kuhlen, M. Selting

- Prosody in Conversation: Interactional Studies

- Cambridge University Press, Cambridge (1996)

4.

- Coupland, 2001

- N. Coupland

- Language, situation, and the relational self: theorizing dialect-style in sociolinguistics

- P. Eckart, J. Rickford (Eds.), Style and Sociolinguistic Variation, Cambridge University Press, Cambridge (2001), pp. 185-210

5.

- Coupland, 2007

- N. Coupland

- Style: Language Variation and Identity

- Cambridge University Press, New York (2007)

6.

- Croom, 2010a

- A. Croom

- Thick concepts, non-cognitivism, and Wittgenstein's rule-following considerations

- South African Journal of Philosophy, 29 (2010), pp. 286-309 
7.

- Croom, 2010b

- Croom, A., 2010b. A game theoretical analysis of slurs and appropriative use. Fourth North American Summer School in Logic, Language, and Information, 26 June, Indiana University. $<$ http://www.indiana.edu/ nasslli/NASSLLlwebprogram.pdf >.

8.

- Croom, 2012b

- Croom, A., 2012b. Face, race, and the psychology of slurring in a cultural context. University of Pennsylvania Program on Democracy, Citizenship, and Constitutionalism Annual Conference, 27 April, University of Pennsylvania.

9.

- Cutler, 2009

- C. Cutler

- "You shouldn't be Rappin”, you should be skateboardin' the X-Games: the construction of Whiteness in an MC Battle

- H. Alim, A. Ibrahim, A. Pennycook (Eds.), Global Linguistic Flows: Hip Hop Cultures, Youth Identities, and the Politics of Language, Routledge, New York (2009), pp. 195-212

10.

- Dawson, 2001

- M. Dawson

- Black Visions: The Roots of Contemporary African-American Political Ideologies

- University of Chicago Press, Chicago (2001)

11.

- Dillard, 1977

- J. Dillard

- Lexicon of Black English

- Seabury, New York (1977)

12.

- Dutton, 2007

- Dutton, E., 2007. "Bog off dog breath! You're talking pants!" Swearing as Witness Evangelism in student Evangelical groups. Journal of Religion and Popular Culture 16.

$<$ http://www.usask.ca/relst/jrpc/art16-swearing-print.html>. 
1.

- Dworkin, 2000

- A. Dworkin

- Against the male flood: censorship, pornography, and equality

- D. Cornell (Ed.), Oxford Readings In Feminism: Feminism and Pornography, Oxford University Press, Oxford (2000), pp. 19-38

2.

- Easton, 2007

- Easton, H., 2007. A Treatise on the Intellectual Character and Civil and Political Condition of the Colored People of the United States; And the Prejudice Exercised Towards Them, Knapp; Boston.

3.

- Echegoyen, 2006

- H. Echegoyen

- The N Word: Divided We Stand

- Post Consumer Media (2006) (Producer)

4.

- Edwards, 1997

- W. Edwards

- The variable persistence of Southern vernacular sounds in the speech of inner-city black Detroiters

- C. Bernstein, T. Nunnally, R. Sabino (Eds.), Language Variety in the South Revisited, University of Alabama Press, Tuscaloosa (1997), pp. 76-86

5.

- Erikson, 1986

- E. Erikson

- Pseudospeciation in the nuclear age

- Political Psychology, 6 (1986), pp. 213-217 
6.

- Fitzmaurice, 2010

- S. Fitzmaurice

- Changes in the meanings of politeness in Eighteenth-century England: discourse analysis and historical evidence

- J. Culpeper, D. Kadar (Eds.), Historical (im)Politeness, Peter Lang, Bern (2010), pp. 87-115

- View Record in Scopus

I

Cited By in Scopus (3)

7.

- Fodor, 1975

- J. Fodor

- The Language of Thought

- Harvard University Press, Cambridge (1975)

8.

- Foley, 1972

- L. Foley

- APhonological and Lexical Study of the Speech of Tuscaloosa County, Alabama

- University of Alabama Press, Tuscaloosa (1972)

9.

- Ford, 1993

- C. Ford

- Grammar in Interaction: Adverbial Clauses in American English Conversations

- Cambridge University Press, Cambridge (1993)

10.

- Fox 10 News, 2010

- Fox 10 News, 2010. Man Gets 25 years to Life for Racial Slur Killing. My Fox Phoenix, 9 December. <http://www.myf oxpho enix.co m/dpp/news/justice/man-gets-25-years-to-lif e-for-racial-slur-killing$12092010>$. 
11.

- Fraleigh and Tuman, 2010

- D. Fraleigh, J. Tuman

- Hate speech

- D. Fraleigh, J. Tuman (Eds.), Freedom of Expression in the Marketplace of Ideas, Sage Publications, London (2010), pp. 139-166

12.

- Fredrickson, 1971

- G. Fredrickson

- The Black Image in the White Mind

- Wesleyan University Press, Middletown (1971)

13.

- Garfinkel, 1967

- H. Garfinkel

- Studies in Ethnomethodology

- Prentice Hall, Englewood Cliffs (1967)

14.

- Gates, 2009

- Gates, H., 2009. 10 Questions. Time, 16 February, 9.

1.

- Goffman, 1967

- E. Goffman

- Interaction Ritual: Essays on Face-to-Face Behavior

- Pantheon, New York (1967)

2.

- Goodall, 2000

- J. Goodall

- Through a Window: My Thirty Years with The Chimpanzees of Gombe

- Mariner, New York (2000) 
3.

- Goodwin, 1979

- C. Goodwin

- The interactive construction of a sentence in natural conversation

- G. Psathas (Ed.), Everyday Language: Studies in ethnomethodology, Irvington, New York (1979), pp. $97-121$

4.

- Goodwin, 2007

- C. Goodwin

- Environmentally coupled gestures

- S. Duncan, J. Cassell, E. Levy (Eds.), Gesture and The Dynamic Dimensions of Language, John Benjamins, Philadelphia (2007), pp. 195-212

5.

- Green, 2002

- L. Green

- Af rican American English: A Linguistic Introduction

- Cambridge University Press, Cambridge (2002)

6.

- Greene, 2011

- Greene, R., 2011. Slurs: Are the Kids All Right? The Economist, 20 September. <http://www.economist.com/blogs/johnson/2011/09/slurs>.

7.

- Grice, 1989

- H. Grice

- Studies in the Way of Words

- Harvard University Press, Cambridge (1989)

8.

- Griffin, 2003

- E. Griffin

- Last Stand

- Urbanworks Entertainment (2003) 
9.

- Gumprz, 1982

- Gumperz, J., 1982. Discourse Strategies, Cambridge University Press; Cambridge.

10.

- Haley, 1964

- A. Haley

- The Autobiography of Malcom X

- Ballantine, New York (1964)

11.

- Harman, 1973

- G. Harman

- Thought

- Princeton University Press, Princeton (1973)

12.

- Hawkins, 1993

- Hawkins, F., 1993. Speaker Ethnic Identification: The Roles of Speech Sample, Fundamental Frequency, Speaker and Listener Variations. Ph.D. Dissertation, University of Maryland, College Park.

13.

- Heath, 2005

- J. Heath

- The Talking Greeks: Speech, Animals, and the Other in Homer, Aeschylus, and Plato

- Harvard University Press, Cambridge (2005)

1.

- Heffernan, 2005

- Heffernan, V., 2005. Epithet Morphs from Bad Girl to Weak Boy. New York Times, 22 March. <http://www.nytimes.com/2005/03/22/arts/television/22chie.html>.

2.

- Heritage, 1984

- J. Heritage

- Garfinkel and Ethnomethodology

- Prentice-Hall, Englewood Cliffs (1984) 
3.

- Hill, 2008

- J. Hill

- The Everyday Language of White Racism

- Wiley Blackwell, Oxford (2008)

4.

- Hollien and Malcik, 1962

- H. Hollien, E. Malcik

- Adolescent voice change in Southern Negro males

- Speech Monographs, 29 (1962), pp. 53-58

- Full Text via CrossRef

5.

- Hoover, 2007

- Hoover, E., 2007. Fighting Words. The Chronicle of Higher Education, 16 February. <http://chronicle.com/article/fighting-words/32405/>.

6.

- Hudson and Holbrook, 1981

- A. Hudson, A. Holbrook

- A study of reading fundamental vocal frequency of young black adults

- Journal of Speech and Hearing Research, 24 (1981), pp. 197-201

7.

- Islam, 2011

- Islam, S., 2011. Faisalabad Bullying Case: Boy Killed Classmate Over 'Homophobic Slur'. The Express Tribune, 6 November. <http://tribune.com.pk/story/288367/faisalabad-bullying-case-boykilled-class mate-over-homophobic-slur/>.

8.

- Jackendoff, 1992

- R. Jackendoff

- Languages of the Mind

- MIT Press, Cambridge (1992) 
9.

- Jackson, 2005

- Jackson, D., 2005. Epithet Stung, Even for Pryor. The Boston Globe, 14 December.

<http://www.boston.com/news/globe/editorial_opinion/oped/articles/2005/12/14/epithet_stung_eve n_for_pryor/>.

10.

- Jacobs, 2001

- H. Jacobs

- Incidents in the Life of a Slave Girl

- Dover, Mineola (2001)

11.

- Jacoby, 1994

- K. Jacoby

- Slaves by nature? Domestic animals and human slaves

- Slavery and Abolition: A Journal of Slave and Post-Slave Studies, 15 (1994), pp. 92-94

12.

- Jay, 1992

- T. Jay

- Cursing in America

- John Benjamins, Philadelphia (1992)

1.

- Jay, 2000

- T. Jay

- Why We Curse: A Neuro-Psycho-Social Theory of Speech

- John Benjamins, Philadelphia (2000)

2.

- Jay-Z, 2002

- Jay-Z, 2002. Bitches and Sisters. The Blueprint 2: The Gift and the Curse. Roc-A-Fella and Def Jam Records. 
3.

- Johnston, 1989

- M. Johnston

- Dispositional theories of value

- Proceedings of the Aristotelian Society Supplementary Volumes, 63 (1989), pp. 139-174

4.

- Jones, 2011

- Jones, S., 2011. Feminist Critics of SlutWalk have Forgotten that Language is not a Commodity. The F Word: Contemporary UK Feminism, 8 June. $<$ http://www.thefword.org.uk/features/2011/06/the_politics_of_slutwalk>.

5.

- Jucker and Taavitsainen, 2003

- A. Jucker, I. Taavitsainen

- Introduction

- I. Taavitsainen, A. Jucker (Eds.), Diachronic Perspectives on Address Term Systems, John Benjamins, Philadelphia (2003), pp. 1-25

- Full Text via CrossRef

6.

- Jun and Foreman, 1996

- Jun, S., Foreman, C., 1996. Boundary tones and focus realization in African-American intonation. 3rd Joint Meeting of the Acoustical Society of America and the Acoustical Society of Japan, Honolulu, HI, December 6.

7.

- Kaplan, 1999

- Kaplan, D., 1999. The Meaning of Ouch and Oops: Explorations in the Theory of Meaning as Use. Unpublished MS. University of California, Los Angeles.

8.

- Kennedy, 2002

- R. Kennedy

- Nigger: The Strange Career of a Troublesome Word

- Vintage Books, New York (2002) 
9.

- Kiefer, 2010

- Kiefer, M., 2010. Man Sentenced in Stomping Death of Woman in Phoenix. The Arizona Republic, 10 December. <http://www.azcentral.com/news/articles/2010/12/09/20101209phoenix-racial-slurslaying-sentence.html>.

10.

- King-Farlow, 1989

- J. King-Farlow

- "Expression" and "expressive" in religious talk for the arts

- Laval theologique et philosophique, 45 (1989), pp. 275-292

- Full Text via CrossRef

11.

- Kratzer, 1999

- Kratzer, A., 1999. Beyond ouch and oops: how descriptive and expressive meaning interact. Cornell Conference on Theories of Context Dependency, 26 March.

$<$ http://semanticsarchive.net/Archive/WEwNGUyO/Beyond\%20\%22Ouch\%22\%20and\%20\%22Oops \%22.pdf >.

1.

- Labov, 1972a

- W. Labov

- Language in the Inner City: Studies in the Black English Vernacular

- University of Pennsylvania Press, Philadelphia (1972)

2.

- Labov, 1972b

- W. Labov

- Rules for ritual insults

- W. Labov (Ed.), Language in the Inner City: Studies in the Black English Vernacular, University of Pennsylvania Press, Philadelphia (1972), pp. 297-353 
3.

- Labov et al., 1968

- W. Labov, P. Cohen, C. Robins, J. Lewis

- A Study of the Non-Standard English of Negro and Puerto Rican Speakers in New York City: Report on Cooperative Research Project 3288

- Columbia University, New York (1968)

4.

- Lakoff, 1987

- R. Lakoff

- Women, Fire, and Dangerous Things: What Categories Reveal about the Mind

- University of Chicago Press, Chicago (1987)

5.

- Larkins, 2006

- Larkins, T., 2006. The N word: Divided We Stand, H. Echegoyen (producer). Post Consumer Media.

6.

- Leech, 1983

○ G. Leech

- Principles of Pragmatics

- Longman, London (1983)

7.

- Leung, 2004

- Leung, R., 2004. Chappelle: 'An Act of Freedom': Comedy Central Comedian Talks about Using the 'N' Word in Jokes. 60 Minutes, CBS News, 29 December. <http://www.cbsnews.com/stories/2004/10/19/60Il/main650149.shtml>.

8.

- Lifton and Humphrey, 1984

- R. Lifton, N. Humphrey

- In a Dark Time

- Harvard University Press, Cambridge (1984) 
9.

- Lindstrom, 1999

- Lindstrom, A., 1999. Language as Social Action: Grammar, Prosody, and Interaction in Swedish Conversation. Ph.D. Dissertation, Uppsala University, Uppsala.

10.

- Loman, 1975

- B. Loman

- Prosodic patterns in a Negro American dialect

- H. Ringbom, A. Ingberg, R. Norrman, K. Nyholm, R. Westman, K. Wikberg (Eds.), Style and Text: Studies Presented to Nils Erik Enkvist, Språkf örlaget Skriptor AB, Stockholm (1975), pp. 219-242

11.

- MacDonald, 2000

- M. MacDonald

- All Souls: A Family Story from Southie

- Ballantine, New York (2000)

12.

- Martin, 2011

- Martin, M., 2011. Beauty Shop: Optional Tax, 'SlutWalk' Opposition. National Public Radio, 26 October. <http://www.npr.org/2011/10/26/141719335/beauty-shop-optional-tax-slutwalkopposition>.

13.

- McDowell, 1996

○ J. McDowell

- Mind and World

- Harvard University Press, Cambridge (1996)

1.

- McLaughlin, 2008

- McLaughlin, E., 2008. Rapper has Defiant Words for New Album. CNN Entertainment, 16 July. <http://www.cnn.com/2008/SHOWBIZ/Music/07/16/music.nas/index.html>.

2.

- Merriam, 2010

- Merriam-Webster., 2010. Xenophobia. <http://www.merriam-webster.com/medical/xenophobia> 
3.

- Messner, 2002

- M. Messner

- Taking the Field: Women, Men, and Sports

- University of Minnesota Press, Minneapolis (2002)

4.

- Miller, 1986

- M. Miller

- The greatest blemish: plurals in -sp, -st, -sk

- M. Montgomery, G. Bailey (Eds.), Language Variety in the South: Perspectives in Black and White, University of Alabama Press, Tuscaloosa (1986), pp. 235-253

5.

- Murray et al., 2011

- Murray, J., Sacks, R., Schimmel, S., 2011. Our Response to the Conversation with Ross Reynolds' Coverage of SlutWalk Seattle on KUOW 94.9 FM. SlutWalk Seattle, 15 May. $<$ http://slutwalkseattle.com/post/5527937600/our-response-to-the-conversation-with-rossreynolds>.

6.

- Ochs, 1992

- E. Ochs

- Indexing gender

- A. Duranti, C. Goodwin (Eds.), Rethinking Context: Language as An Interactive Phenomenon, Cambridge University Press, New York (1992), pp. 335-358

7.

- Ochs et al., 1996

- E. Ochs, E. Schegloff, S. Thompson

- Interaction and Grammar

- Cambridge University Press, Cambridge (1996) 
8.

- Ochs and Schieffelin, 1984

- E. Ochs, B. Schieffelin

- Language acquisition and socialization: three developmental stories and their implications

- R. Shweder, R. LeVine (Eds.), Culture Theory: Essays in Mind, Self and Emotion, Cambridge University Press, New York (1984), pp. 276-320

9.

- Parker-Ryan, 2012

- Parker-Ryan, S., 2012. Ordinary Language Philosophy. Internet Encyclopedia of Philosophy. <http://www.iep.utm.edu/ord-lang/>.

10.

- Patterson, 1985

- O. Patterson

- Slavery and Social Death: A Comparative Study

- Harvard University Press, Cambridge (1985)

11.

- Pederson et al., 1986-1992

- Pederson, L., McDaniel, S., Bailey, G., Basset, M., Adams, C., Liao, C., Montgomery, M., 1986-1992. The Linguistic Atlas of the Gulf States, vol. 7. University of Georgia Press, Athens.

12.

- Potts, 2007

- C. Potts

- The expressive dimension

- Theoretical Linguistics, 33 (2007), pp. 165-197

13.

- Potts, 2008

- C. Potts

- The pragmatics of conventional implicature and expressive content

- C. Maienborn, P. Portner (Eds.), Semantics: An International Handbook of Natural Language Meaning, Mouton de Gruyter, Berlin (2008) (Chapter 94) 
1.

- Rahman, 2004

- Rahman, J., 2004. It's a Serious Business: The Linguistic Construction of Middle Class White Characters by African American Narrative Comedians. Ph.D. Dissertation, Stanford University, Stanford.

2.

- Rahman, 2012

- J. Rahman

- The $\mathrm{N}$ word: its history and use in the African American community

- Journal of English Linguistics, 40 (2012), pp. 137-171.

3.

- Richard, 2008

- M. Richard

- When Truth Gives Out

- Oxford University Press, Oxford (2008)

4.

- Rosch, 1988

- E. Rosch

- Coherences and categorization: a historical view

- F. Kessel (Ed.), The Development of Language and of Language Researchers: Papers Presented to Roger Brown, Erlbaum, Hillsdale (1988), pp. 373-392

5.

- Ratliff, 2008

- B. Ratliff

- The Jazz Ear: Conversations over Music

- Henry Holt and Company, New York (2008)

6.

- Sabo, 2001

- D. Sabo

- Doing time, doing masculinity: sports and prison

- D. Sabo, T. Kupers, W. London (Eds.), Prison Masculinities, Temple University Press, Philadelphia (2001), pp. 61-66 
7.

- Saka, 2007

- P. Saka

- How to Think About Meaning

- Springer, Netherlands (2007)

8.

- Samra-Fredericks, 2003

- D. Samra-Fredericks

- Strategizing as lived experience and strategists everyday efforts to shape strategic direction

- Journal of Management Studies, 40 (2003), pp. 141-174

- Full Text via CrossRef

9.

- Schillinger, 2010

- Schillinger, L., 2010. Sexual Politics: Book Review of "Big girls Don't Cry: The Election that Changed Everything for American Women" by Rebecca Traister. The New York Times, Sunday Book Review, 16 September. <http://www.nytimes.co m/2010/09/19/books/review/Schillinger-t.html? pagewanted=all>.

10.

- Schneider and Katz, 2011

- Schneider, S., Katz, M., 2011. Rethinking the Language of Thought. Wiley Reviews Cognitive Science. <http://dx.doi.org/10.1002/wcs.115>.

11.

- Shields, 2007

- C. Shields

- Aristotle

- Routledge, New York (2007)

12.

- Siemaszko, 2011

- Siemaszko, C., 2011. S.I. Dad Says Marine Son Victim of Hate, Just Like Chen. New York Daily News, 24 December. <http://articles.nydailynews.com/2011-12-24/news/30555596_1_suicide-notedad-danielle>. 
1.

- Smith, 2011

- D. Smith

- Less than Human: Why We Demean, Enslave, and Exterminate Others

- St. Martin's Press, New York (2011)

2.

- Smith and Medin, 1981

- E. Smith, D. Medin

- Categories and Concepts

- Harvard University Press, Cambridge (1981)

3.

- Smitherman, 2000

- G. Smitherman

- Black Talk: Words and Phrases from the Hood to the Amen Corner

- Houghton Mifflin, Boston (2000)

4.

- Sniderman and Piazza, 2002

- P. Sniderman, T. Piazza

- Black Pride and Black Prejudice

- Princeton University Press, Princeton (2002)

5.

- Sorjonen, 2001

- M. Sorjonen

- Responding in Conversation: A Study of Response Particles in Finnish

- John Benjamins, Philadelphia (2001)

6.

- Stampler, 2011

- Stampler, L., 2011. SlutWalks Sweep the Nation. Huffington Post, 20 April.

<http://www.huffingtonpost.com/2011/04/20/slutwalk-united-states-city_n_851725.html>. 
7.

- Stuckey, 1994

- S. Stuckey

- Going Through the Storms: The Influence of African American Art in History

- Oxford University Press, New York (1994)

8.

- Szekely, 2008

- L. Szekely

- Offensive Words. Chewed Up

- Image Entertainment, Los Angeles (2008)

9.

- Tannen, 1993

- D. Tannen

- The relativity of linguistic strategies: rethinking power and solidarity in gender and dominance

- D. Tannen (Ed.), Gender and Discourse, Oxford University Press, Oxford (1993), pp. 19-52

10.

- Thomas and Reaser, 2004

- E. Thomas, J. Reaser

- Delimiting perceptual cues used for the ethnic labeling of African American and European American voices

- Journal of Sociolinguistics, 8 (2004), pp. 54-87

11.

- Twain, 1986

- M. Twain

- The Adventures of Huckleberry Finn

- Scholastic Inc., New York (1986)

12.

- Vygotsky, 1962

- L. Vygotsky

- Thought and Language

- MIT Press, Cambridge (1962) 
1.

- White House, 2009

- White House, 2009. Andrew Jackson. The White House.

<http://www.whitehouse.gov/about/presidents/andrewjackson>.

2.

- Wilkinson, 2011

- Wilkinson, E., 2011. Racial Slur Led to Killing of Innocent Teen. King 5 News, 9 December. <http://www.king5.com/news/lo cal/Racial-slur-led-to-killing-of-innocent-teen-135354268.html>.

3.

- Williams, 1985

- B. Williams

- Ethics and the Limits of Philosophy

- Harvard University Press, Cambridge (1985)

4.

- Williams, 2008

- K. Williams

- It's Pimpin' Pimpin'

- Salient (2008)

5.

- Williamson, 1968

- J. Williamson

- APhonological and Morphological Study of the Speech of the Negro in Memphis, Tennessee

- University of Alabama Press, Tuscaloosa (1968)

6.

- Wilson, 2002

- H. Wilson

- Henry Louis Gates (Ed.), Our Nig: Or Sketches from the Life of a Free Black (third ed.), Vintage Books, New York (2002) 
7.

- Wittgenstein, 1953

○ L. Wittgenstein

- Philosophical Investigations

- Blackwell, Oxford (1953)

8.

- Wolfram, 1969

- W. Wolfram

- A Sociolinguistic Description of Detroit Negro Speech

- Center for Applied Linguistics, Washington (1969)

9.

- Wolfram and Fasold, 1974

- W. Wolfram, R. Fasold

- The Study of Social Dialects in the United States

- Prentice Hall, Englewood Cliffs (1974)

10.

- Wolfram and Thomas, 2002

- W. Wolfram, E. Thomas

- The Development of African American English

- Blackwell, Oxford (2002)

11.

- Zizek, 2007

- S. Zizek

- Violence: Big Ideas/Small Books

- Picador, New York (2007)

\section{Vitae}

Adam M. Croom is a Guest Associate Editor for Frontiers in Theoretical and Philosophical Psychology. He was educated at Penn and Harvard, and has conducted empirical research at Penn, Yale, Columbia, and UCSD. His published work offers original contributions to several academic disciplines including philosophy, psychology, and linguistics, and his interdisciplinary research has been commended with numerous awards from the University of Pennsylvania, the Phi Beta Kappa Society, and the Andrew W. Mellon Foundation. Adam is a native of Redondo Beach, California, and a combat veteran of the United States Air Force (2000-2004). Find his work 
at:(http://upenn.academia.edu/adamcroom) or (http://adamcroom.me/).

Copyright (C) 2013 Published by Elsevier Ltd. 